\title{
ARTICLE
}

\section{Actin activates Pseudomonas aeruginosa ExoY nucleotidyl cyclase toxin and ExoY-like effector domains from MARTX toxins}

\author{
Alexander Belyy ${ }^{1,2, \star}$, Dorothée Raoux-Barbot ${ }^{1, \star}$, Cosmin Saveanu $^{3, \star}$, Abdelkader Namane $^{3}$, Vasily Ogryzko ${ }^{4}$, \\ Lina Worpenberg ${ }^{1}$, Violaine David ${ }^{5}$, Veronique Henriot ${ }^{5}$, Souad Fellous ${ }^{5}$, Christien Merrifield ${ }^{5}$, Elodie Assayag ${ }^{1}$, \\ Daniel Ladant ${ }^{1}$, Louis Renault ${ }^{5}$ \& Undine Mechold ${ }^{1}$
}

The nucleotidyl cyclase toxin ExoY is one of the virulence factors injected by the Pseudomonas aeruginosa type III secretion system into host cells. Inside cells, it is activated by an unknown eukaryotic cofactor to synthesize various cyclic nucleotide monophosphates. ExoY-like adenylate cyclases are also found in Multifunctional-Autoprocessing Repeats-in-ToXin (MARTX) toxins produced by various Gram-negative pathogens. Here we demonstrate that filamentous actin (F-actin) is the hitherto unknown cofactor of ExoY. Association with F-actin stimulates ExoY activity more than 10,000 fold in vitro and results in stabilization of actin filaments. ExoY is recruited to actin filaments in transfected cells and alters F-actin turnover. Actin also activates an ExoY-like adenylate cyclase MARTX effector domain from Vibrio nigripulchritudo. Finally, using a yeast genetic screen, we identify actin mutants that no longer activate ExoY. Our results thus reveal a new sub-group within the class II adenylyl cyclase family, namely actin-activated nucleotidyl cyclase (AA-NC) toxins.

\footnotetext{
${ }^{1}$ Institut Pasteur, CNRS UMR3528, Unité de Biochimie des Interactions Macromoléculaires, Département de Biologie Structurale et Chimie, 25-28 rue du Docteur Roux, 75724 Paris cedex 15, France. ${ }^{2}$ Department of Bacterial Infections, Gamaleya Research Center, Moscow 123098, Russia. ${ }^{3}$ Institut Pasteur, CNRS UMR3525, Génétique des Interactions Macromoléculaires, Département de Génomes et Génétique, 25-28 rue du Docteur Roux, 75724 Paris cedex 15, France. ${ }^{4}$ Institut Gustave Roussy, CNRS UMR 8126, Unité de Signaling, Nuclei and Innovations in Oncology, 94805 Villejuif, France. ${ }^{5}$ Institute for Integrative Biology of the Cell (I2BC), CEA, CNRS, Univ. Paris-Sud, Université Paris-Saclay, 91198 Gif-sur-Yvette cedex, France. * These authors contributed equally to this work. Correspondence and requests for materials should be addressed to L.R. (email: louis.renault@i2bc.paris-saclay.fr) or to U.M. (email: undine.mechold@pasteur.fr).
} 
P seudomonas aeruginosa is an opportunistic human pathogen that causes severe infections in immune-compromised individuals and is a major cause of chronic infections in cystic fibrosis patients. Equipped with a type III secretion system (T3SS), $P$. aeruginosa can inject effector proteins directly into host cells where they contribute to virulence of the pathogen (for reviews see refs 1,2). Four different T3SS-delivered effectors have been characterized (exoenzyme T, Y, U and S), but new effectors were recently identified ${ }^{3}$. Exoenzyme $\mathrm{Y}$ (ExoY) is present in $89 \%$ of clinical isolates ${ }^{4}$. It was originally identified as an adenylate cyclase in 1998 due to amino-acid sequence homology with two well-characterized class II adenylate cyclase toxins, CyaA from Bordetella pertussis and edema factor from Bacillus anthracis ${ }^{5}$. Recent studies employing cultured cells revealed that substrate specificity of these enzymes is not restricted to ATP: edema factor and CyaA were shown to use uridine- $5^{\prime}$-triphosphate (UTP) and cytidine- $5^{\prime}$-triphosphate (CTP) as substrate ${ }^{6}$ while ExoY was shown to promote the intracellular accumulation of several cyclic nucleotides ${ }^{7,8}$ with a preference for cyclic GMP (cGMP) and cyclic UMP (cUMP) over cyclic AMP (cAMP) and cyclic CMP (cCMP) formation ${ }^{7}$.

ExoY was shown to induce cell death in a cellular infection model $^{9}$ and severe, long-term lung damage in an animal infection model in rats ${ }^{10}$. At the molecular level, ExoY was associated with microtubule breakdown causing the formation of gaps between endothelial cells and increased permeability of the endothelial barrier ${ }^{8,11-13}$. These effects were, however, not seen in all studies $^{14,15}$ and could be attributed to different expression levels of ExoY, as well as the use of different bacterial strain backgrounds and cell lines.

Recent whole-genome sequencing projects have identified ExoY nucleotidyl cyclase modules among a variety of toxic Multifunctional-Autoprocessing Repeats-in-ToXin (MARTX) effector domains in numerous bacterial species of the Vibrio genus $^{16}$ that represent emerging human or animal pathogens. These ExoY-like domains can be essential for virulence ${ }^{16}$. Elucidating the enzymatic specificities and molecular mechanisms of pathogenicity of ExoY and ExoY-like toxins may, therefore, help finding new therapeutic strategies against the toxicity and virulence of several bacterial pathogens.

Despite the progress in understanding downstream effects of ExoY activity, fundamental information on ExoY is lacking: similar to other bacterial soluble related cyclases such as CyaA and edema factor, ExoY is inactive in bacteria and is activated by an unknown eukaryotic cofactor after its delivery to the target cells ${ }^{5}$. Whereas the other class II adenylate cyclase toxins such as CyaA and edema factor are strongly activated upon interaction with calmodulin ${ }^{17,18}$, calmodulin is unable to stimulate ExoY enzymatic activity and the precise nature of the eukaryotic activator has remained elusive up to now. Here we report the identification of actin as the cofactor that activates $P$. aeruginosa ExoY and the ExoY-like module present in MARTX toxin of Vibrio nigripulchritudo in host cells. Our findings suggest that actin is the common eukaryotic activator for a sub-group of the class II adenylyl cyclase toxin family ${ }^{19}$.

\section{Results}

An activator of ExoY is present in Saccharomyces cerevisiae. Arnoldo et al. ${ }^{20}$ have reported that overexpression of ExoY impairs yeast growth, suggesting that ExoY is active in this organism and, therefore, that a cofactor required for ExoY catalytic activity should be present in yeast. To test this hypothesis, we prepared extracts from Saccharomyces cerevisiae BY4741 cells and measured adenylate cyclase activity of recombinant ExoY carrying an N-terminal His-Flag tag (HF-ExoY) in the presence of increasing amounts of yeast cell extracts in vitro. Extracts from HeLa cells were used as positive control. We observed a dose-dependent stimulation of ExoY activity by yeast cell extracts, to levels that were similar to those measured when using HeLa cell extracts (Fig. 1a). Thus, we decided to use $S$. cerevisiae as a convenient experimental system to identify the putative yeast activator that was likely to be evolutionarily conserved in human cells.

Actin interacts with ExoY-TAP in S. cerevisiae. To identify putative ExoY-binding proteins in yeast, plasmid-encoded ExoY with either a C-terminal TAP- or HA-tag (ExoY-TAP or ExoY-HA, respectively) was expressed in S. cerevisiae. To avoid toxic effects due to cyclic nucleotide accumulation, we used a catalytically inactive variant of ExoY, ExoY ${ }^{\mathrm{K} 81 \mathrm{M}}$ (in which the Lys81 was mutated to $\left.\mathrm{Met}^{5}\right)$. Proteins co-purifying with the affinity purified bait protein were isolated by affinity purification on rabbit IgGs covalently bound to magnetic beads and analysed by SDS-polyacrylamide gel electrophoresis (PAGE) (Supplementary Fig. 1), or processed by tryptic digestion and liquid chromatography-mass spectrometry (LC-MS/MS)

a

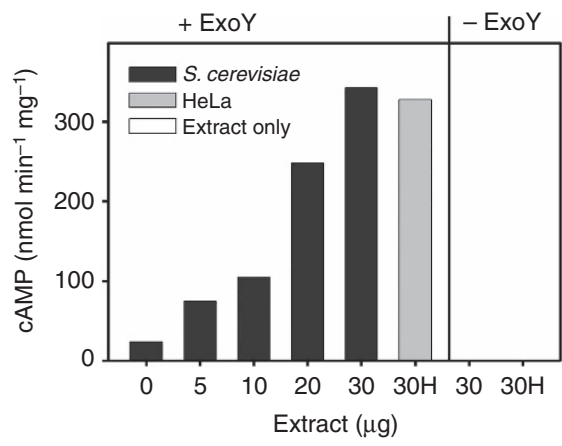

b

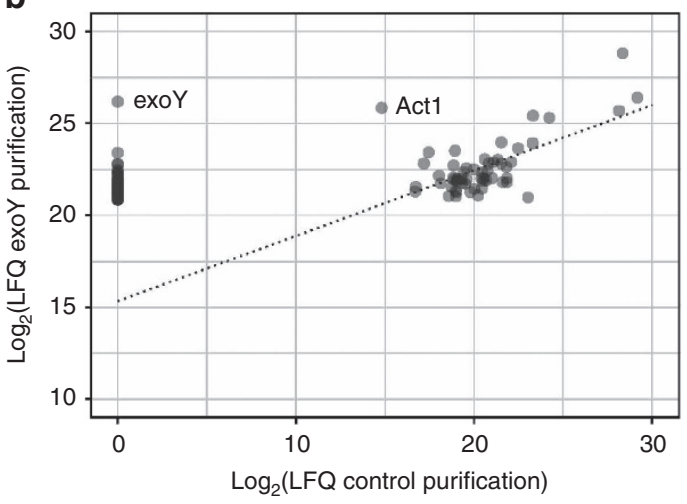

Figure 1 | Presence of an activator of ExoY in Saccharomyces cerevisiae. (a) Activation of HF-ExoY by extracts from HeLa cells or S. cerevisiae. Reactions $(50 \mu \mathrm{l})$ containing $1 \mu \mathrm{g}$ ExoY were started by the addition of $2 \mathrm{mM}$ ATP substrate and stopped after $30 \mathrm{~min}$ incubation at $30^{\circ} \mathrm{C}$ and the amount of synthesized CAMP was measured. (b) Specific association of yeast Act1 to ExoYK81M. Log $_{2}$ transformed LFQ scores for the proteins identified in the fraction that copurified with ExoYK81M_TAP ( $y$ axis) were represented as a function of the scores obtained for the control purification (ExoY ${ }^{K 81 M}-H A, x$ axis). Black circles are the result of two or more superimposed grey circles. For clarity, only the 100 proteins with highest LFQ scores in the TAP purification are shown. Forty-five of these factors, including ExoY, were not identified in the control purification and are represented on the $y$ axis alone. The dashed line was computed by linear regression for the 55 proteins having LFQ values in both experiments and indicates the trend for common contaminants in the affinity purification. 
peptide/protein analysis. The raw data were then analysed by MaxQuant for protein identification and quantitative estimation of the specific enrichment of proteins in the experimental sample (ExoY ${ }^{\mathrm{K}^{2} 1 \mathrm{M}_{-} \mathrm{TAP}}$ ) as compared with the control (ExoY ${ }^{\mathrm{K} 81 \mathrm{M}_{-} \mathrm{HA}}$ ). While many abundant proteins were present in both samples to a similar degree, as estimated from the label-free quantitation score $\left(\mathrm{LFQ}^{21}\right)$, ExoY was identified exclusively in the purification performed with ExoY ${ }^{\mathrm{K} 81 \mathrm{M}}$-TAP extracts, as expected. Another protein that was about 1,000 times more abundant in the ExoY $\mathrm{K}^{\mathrm{K} 1 \mathrm{M}_{-} \mathrm{TAP}}$ purification than in the control was yeast actin (Uniprot P60010, YFL039C, Act1), which showed an LFQ score close to the score of the tagged ExoY (Fig. 1b). Other factors were identified specifically in the ExoY $\mathrm{K}^{\mathrm{K} 1 \mathrm{M}_{-} \mathrm{TAP}}$ purification, but with much lower LFQ scores (see Supplementary Data 1). These results suggested a specific interaction of ExoY ${ }^{\mathrm{K} 81 \mathrm{M}}$ with actin. Since actin is both specific to eukaryotic cells and one of the most highly conserved and abundant proteins in these cells, actin appeared to be an appropriate candidate for activating ExoY in mammalian cells.

ExoY interacts with mammalian actin filaments in vitro. To verify the interaction between ExoY and mammalian actin in vitro, we performed Ni-NTA agarose pulldowns using ExoY with a C-terminal Flag-His tag (ExoY-FH) and $\alpha$-actin from rabbit skeletal muscle. Binding of ExoY to polymerized actin (F-actin, Fig. 2a) or to monomeric actin (G-actin) that was prevented from polymerization by the drug latrunculin $\mathrm{A}$ (Fig. 2b) was tested. While no binding of G-actin to ExoY could be observed (EA, Fig. 2b), quantitative densitometry analysis showed that $92 \%$ of F-actin and $100 \%$ of ExoY could be recovered by elution (elu) from samples that contained both proteins (EA, Fig. 2a). The unspecific binding of F-actin to Ni-agarose beads was low under the conditions tested as $85 \%$ of F-actin was found in the unbound fraction ( $\mathrm{fth}$ ) in samples containing only F-actin (A, Fig. 2a).

To confirm ExoY binding to F-actin, we performed high-speed cosedimentation assays using mixtures of ExoY and F-actin polymerized to steady state. High-speed centrifugation separated F-actin present in the pellet from G-actin present in the supernatant. Figure $2 \mathrm{c}$ shows that ExoY, which alone partitioned into the supernatant, was mostly found in the pellet fraction in the presence of F-actin, providing additional evidence that ExoY can interact with F-actin.

Actin stimulates ExoY nucleotidyl cyclase activity in vitro. We next tested whether purified actin could activate ExoY in vitro. We used buffer conditions allowing actin self-assembly to proceed above the critical concentration for polymerization. Highly pure non-muscle (cytoplasmic) actin isolated from human platelets (Cytoskeleton, Inc., designated here A-99) strongly stimulated the adenylate cyclase activity of ExoY (HF-ExoY), with a maximal activity reaching $120 \mu \mathrm{mol}$ of $\mathrm{cAMP} \mathrm{min}^{-1} \mathrm{mg}^{-1}$ (Fig. 3a). Since expression of ExoY in transfected mammalian cells led to accumulation of cGMP to levels exceeding that of $\mathrm{cAMP}^{7,8}$, we also tested GTP as substrate. We found that the guanylate cyclase activity of HF-ExoY was $\sim 8$ times higher than the adenylate cyclase activity in the presence of actin in vitro (Fig. 3a). The background activity without actin was estimated to

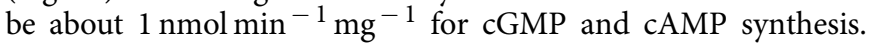
Thus, the ExoY nucleotidyl cyclase activity was stimulated more than 10,000 fold by submicromolar concentrations of actin. Different mammalian actin isoforms (A-99 consisting of $85 \%$ $\beta$ - and $15 \% \gamma$-actin, or $\alpha$-actin from rabbit skeletal muscle) were tested and all found to strongly activate ExoY-catalysed synthesis of cGMP in a concentration dependent manner (Supplementary Fig. 2), indicating that they were all effective activators of
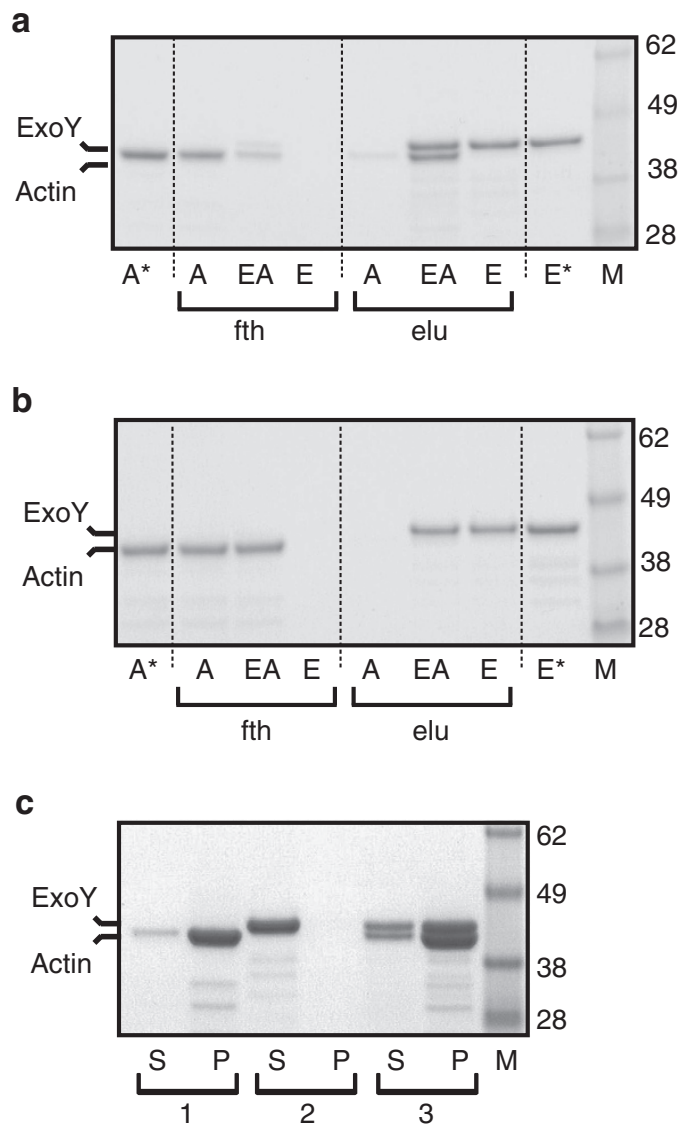

Figure 2 | Interaction between ExoY and skeletal muscle actin from

rabbit. (a,b) Actin (MA-L) was converted to Mg-ATP actin and allowed to polymerize to steady state at $20 \mu \mathrm{M}$ for $2 \mathrm{~h}$ at room temperature (a) or prevented from polymerization by the addition of latrunculin $\mathrm{A}$ to $30 \mu \mathrm{M}$ (b), then diluted fivefold in binding buffer ( $20 \mathrm{mM}$ imidazole) and added to $7.5 \mu \mathrm{l} \mathrm{Ni-NTA}$ agarose beads. Equimolar amounts $(12 \mu \mathrm{g})$ of ExoY-FH or the corresponding buffer were added and binding was allowed in batch for $1 \mathrm{~h}$ at $4^{\circ} \mathrm{C}$. Samples were washed three times with buffer containing $20 \mathrm{mM}$ imidazole and once in buffer containing $40 \mathrm{mM}$ imidazole before elution in SDS-sample buffer. Aliquots were separated on 4-12\% NuPAGE Bis-Tris gels (Invitrogen) in NuPAGE MES SDS running buffer and the gel was stained with Bio-Safe Coomassie stain. Lanes (A): actin only; $(E)$ : ExoY only; $(A E)$ : both actin and ExoY-FH; $\left(A^{\star}\right)$ and $\left(E^{\star}\right)$ : corresponding input for actin and ExoY alone, respectively; (fth): flow through, that is, fraction not bound to Ni-NTA beads; (elu): fractions eluted from Ni-NTA agarose.

Corresponding amounts were loaded to allow direct comparability. Aliquots correspond to $10 \%$ of the total sample volume. The band of lower molecular weight was confirmed to be actin by western blots with anti-actin C4 antibodies. (c) Cosedimentation of ExoY with skeletal muscle F-actin (MA-99). Supernatant (S) and pellet (P) fractions were separated on 4-12\% NuPAGE Bis-Tris gels (Invitrogen) in NuPAGE MES SDS running buffer and the gel was stained as above. Reaction (1): actin only,

(2): ExoY-FH only, (3) actin plus ExoY-FH.

ExoY. Subsequent experiments were performed using $\alpha$-actin from rabbit skeletal muscle purified in our laboratory and fully functional in actin polymerization assays ( $>95 \%$ pure, designated MA-L).

To examine a possible dependence of ExoY activation on the different states of actin (ATP- versus ADP-bound, monomeric versus polymeric forms), we measured cGMP synthesis activity of ExoY at different actin concentrations below or above the critical concentrations that favor actin self-assembly in these different nucleotide states. Measurements were performed at increasing 
a

b
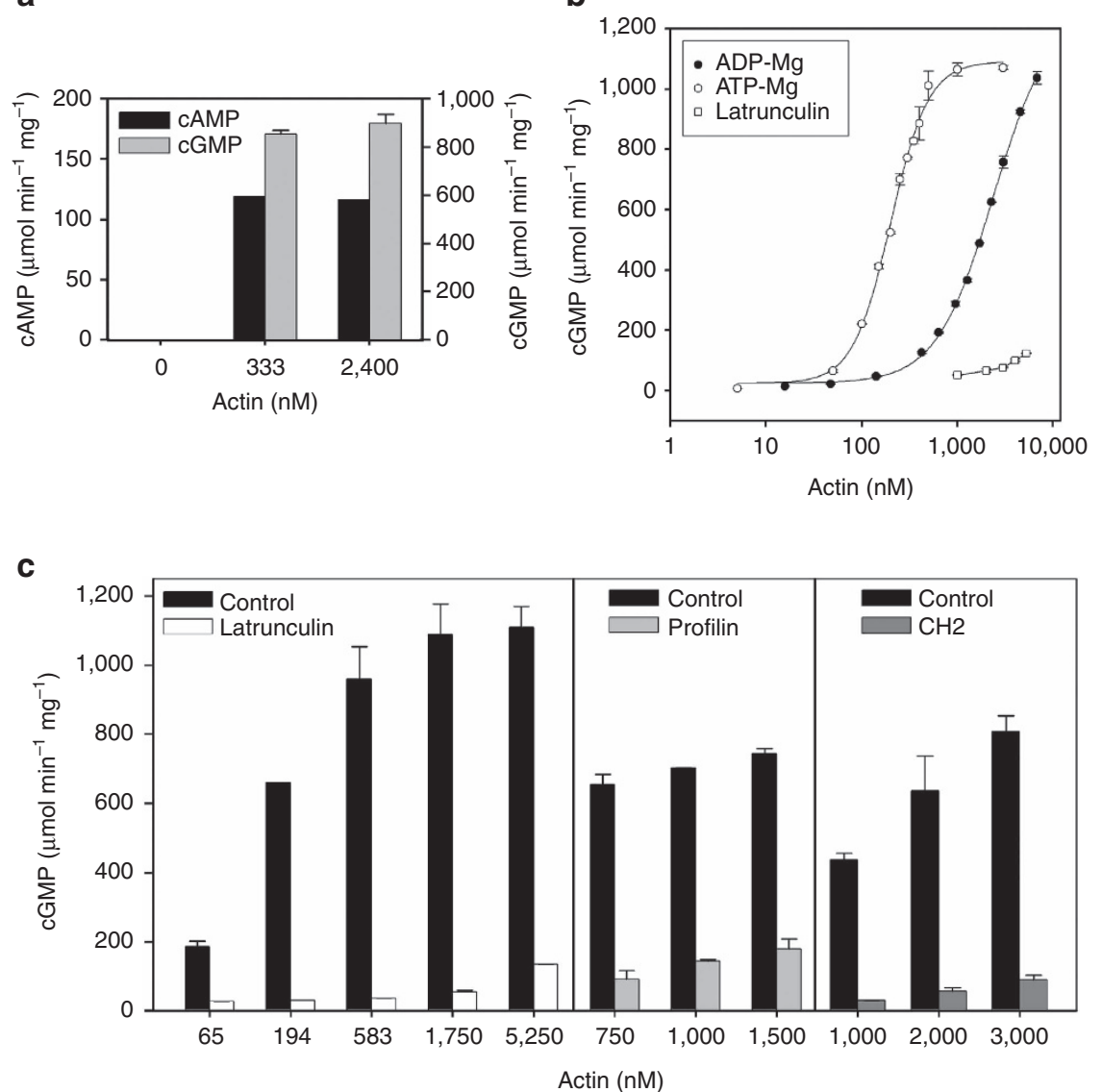

Figure 3 | ExoY is efficiently activated by actin in vitro. (a) Preferential synthesis of cGMP as compared with cAMP by ExoY activated by actin (A-99). Reactions containing HF-ExoY at $0.5 \mathrm{nM}(1 \mathrm{ng})$ and actin at concentrations indicated were started by the addition of $2 \mathrm{mM}$ ATP or GTP substrate and incubated for $10 \mathrm{~min}$ at $30^{\circ} \mathrm{C}$. (b) Dependence of ExoY activation on the nucleotide and polymerization state of actin. Muscle $\alpha$-actin (MA-L) was converted to Mg-ATP-actin or Mg-ADP-actin and used at the concentration indicated to activate ExoY-FH. Mg-ATP-actin or Mg-ADP-actin polymerize above 100 and 2,000 nM, respectively. Activities with Mg-ATP-actin monomers saturated by the polymerization-inhibiting drug latrunculin A (according to $\mathbf{c}$ ) were plotted as comparison. (c) Effect of latrunculin A and G-actin-binding proteins on the activation of ExoY. Reactions containing actin $\left(+/-\right.$ Latrunculin $\mathrm{A}$ ) and ExoY-FH were preincubated for $10 \mathrm{~min}$ at $30^{\circ} \mathrm{C}$ and started by the addition of $2 \mathrm{mM} \mathrm{GTP}$ and continued for $10 \mathrm{~min}$. Latrunculin A: Latrunculin $A$ was present at a twofold excess over actin (MA-L) and was added to actin and preincubated for 10 min at room temperature before conversion to Mg-ATP-actin and processing as for the control. Profilin: Profilin was added to Ca-ATP-G-actin at a 2:1 ratio. Control reactions lacking latrunculin or profilin contained G-actin (MA-L) that was converted to Mg-ATP-G-actin and allowed to polymerize to steady state conditions before dilution to the indicated concentrations. Chimera 2 of T $\beta 4$ (Chim2-T $\beta 4$ ) for a final concentration of $5 \mu \mathrm{M}$ was added to muscle G-actin (MA-L) under conditions preventing salt-induced polymerization in G-buffer and preincubated for $10 \mathrm{~min}$ at $30^{\circ} \mathrm{C}$. None of the molecules tested affected the low basal ExoY activity in the absence of actin. Error bars correspond to s.d. of two experimental replicates.

concentrations of actin that was initially loaded with either $\mathrm{Mg}$ ATP or Mg-ADP. A similar maximal activity of 1,000-1,200 $\mu \mathrm{mol}$ of cGMP min $^{-1} \mathrm{mg}^{-1}$ was obtained with both ATP- and ADPbound actin (Fig. 3b). In contrast, the actin concentrations required for half maximal activation of ExoY $\left(\mathrm{K}_{1 / 2}\right)$ were dependent on the bound nucleotides: half maximal ExoY activation was obtained using $0.2 \mu \mathrm{M}$ of ATP-loaded actin (Fig. 3b), just above the critical concentration of $0.1 \mu \mathrm{M}$ at which $\mathrm{Mg}$-ATP-actin spontaneously polymerizes with salt. Conversely, half-maximal ExoY activation was obtained at about $2.4 \mu \mathrm{M}$ ADP-loaded actin (Fig. 3b), a value close to the critical spontaneous polymerizing concentration (about $2 \mu \mathrm{M}$ ) of $\mathrm{Mg}$-ADP-actin ${ }^{22}$. Altogether, these results suggest that the maximal activation of ExoY by actin was correlated with F-actin formation.

Effect of latrunculin A and G-actin-binding proteins. We examined whether proteins or molecules known to bind to G-actin and to inhibit elongation and/or spontaneous nucleation, alter the activation of ExoY by actin. We used latrunculin A or the abundant G-actin-binding proteins profilin and thymosin- $\beta 4$ (T $\beta 4$ ). These three molecules are known to bind to distinct G-actin interfaces: (i) The small macrolide latrunculin $\mathrm{A}^{23,24}$ inhibits actin self-assembly by binding $\left(K_{\mathrm{d}} \sim 0.2 \mu \mathrm{M}\right)$ to a cleft located on the pointed face of G-actin. (ii) Profilin binds $\left(K_{\mathrm{d}} \sim 0.1 \mu \mathrm{M}\right)$ to the opposite face of monomers, called barbed face, and favors in vivo the unidirectional elongation of the mostdynamic barbed ends of filaments. In vitro, G-actin:profilin complexes inhibit actin spontaneous nucleation and thus polymerization in the absence of actin nuclei or filament seeds. (iii) T 34 acts as a major G-actin-sequestering polypeptide in cells $^{25,26}$. Here we used a chimeric $\beta$-thymosin domain, chim2-T $\beta 4$ (a chimera between bovine T $\beta 4$ and Drosophila ciboulot made of $\beta$-thymosin repeats), which sequesters $G$-actin monomers with higher affinity than $\mathrm{T} \beta 4\left(K_{\mathrm{d}} \sim 0.5 \mu \mathrm{M}\right.$ versus $2 \mu \mathrm{M})^{25,26}$. As with T $\beta 4$, the binding interface of chim2-T $\beta 4$ with actin monomers is extensive, covering both the barbed and pointed faces ${ }^{25,26}$. 
Actin monomers were saturated with these molecules to inhibit the spontaneous nucleation or polymerization of actin. As shown in Fig. 3c, latrunculin A, profilin and chim2-T $\beta 4$, all efficiently inhibited ExoY activation by actin at concentrations that fully activate the enzyme in control assays. These data thus provide additional indications that filamentous actin is the preferred activator of ExoY.

ExoY binding along actin filaments alters their turnover. We examined whether ExoY interaction with actin alters the intrinsic or regulated dynamics of actin self-assembly in vitro. To avoid indirect effects of ATP depletion due to ExoY activity, we used the inactive variant ExoY ${ }^{\mathrm{K} 81 \mathrm{M}}$ in assembly/disassembly kinetic studies with G-/F-actin-ATP. Alternatively, wild-type ExoY was used in kinetic studies with G-/F-actin-ADP, since ADP is not an ExoY substrate. The kinetics of polymerization or depolymerization were monitored by following the increase or decrease, respectively, of pyrene-actin fluorescence intensity (pyrenyllabelled actin subunits exhibit higher fluorescence when incorporated in filaments than free in solution). In polymerization assays, ExoY $\mathrm{K}^{\mathrm{N} 1 \mathrm{M}}$ slightly accelerated the rate of G-actin-ATP-Mg or G-actin-ADP-Mg self-assembly (Fig. 4a, Supplementary Fig. 4), confirming that ExoY interacts with actin without preventing actin self-assembly. Yet, this stimulation of G-actinATP/ADP polymerization by ExoY was detected only at high ExoY concentrations (in $\mu \mathrm{M}$ range). Besides, ExoY-stimulated actin polymerization was abolished when G-actin was saturated by profilin (Fig. 4a). In eukaryotic cells, the polymerization competent G-actin pool is mainly bound to profilin ${ }^{22,27}$. Therefore, these results indicate that ExoY is unlikely to stimulate actin polymerization in host cells. To delineate the interaction of ExoY with F-actin, we performed filament disassembly assays monitored from free barbed- or pointedends. As shown in Fig. 4b, ExoY ${ }^{\mathrm{K} 81 \mathrm{M}}$ inhibited spontaneous F-actin disassembly induced by dilution. This inhibition was also observed when barbed ends were capped by gelsolin (Fig. 4b), thus excluding the possibility that ExoY inhibited disassembly by binding to barbed ends. These results, as well as the absence of ExoY effects on pointed and barbed-end elongation rates (Supplementary Fig. 5), indicate that ExoY binds along the sides of filaments. ExoY thus stabilizes actin inter-subunit contacts by interacting with adjacent subunits and prevents spontaneous disassembly of filaments.

The binding of ExoY and ExoY $\mathrm{K}^{\mathrm{K} 1 \mathrm{M}}$ to filamentous actin was quantified by cosedimentation assays using F-actin steadily polymerized in the presence of $\mathrm{ADP}-\mathrm{BeF}_{3}^{-}$(mimicking the ADP-Pi state of filaments) in order to keep most actin firmly polymerized despite the efficient conversion of ATP into cAMP by activated ExoY. Because ExoY and actin (43 and $42 \mathrm{kDa}$, respectively) cannot be well separated by SDS-PAGE, we used an ExoY protein fused to the maltose-binding-protein (MBP), MBP-ExoY. Cosedimentation assays were performed at constant concentration of $\mathrm{F}$-actin using increasing concentrations of MBP-ExoY/ExoY ${ }^{\mathrm{K} 81 \mathrm{M}}$. As shown in Fig. 4c, MBP-ExoY or MBP-ExoY ${ }^{\mathrm{K} 81 \mathrm{M}}$ alone partitioned into the supernatant (lanes 1 and 2). The proteins that cosedimented with F-actin gradually increased with increasing MBP-ExoY/ExoY K81M concentrations up to a saturation corresponding to an ExoY:actin stoichiometry of 1:1 (Fig. 4c, right panel). The estimated dissociation constants $\left(K_{\mathrm{d}}\right)$ of MBP-ExoY and MBP-ExoY ${ }^{\mathrm{K} 81 \mathrm{M}}$ for F-actin-ADP-BeF${ }_{3}^{-}$ $(1.0 \pm 0.2 \mu \mathrm{M}$ and $1.6 \pm 0.3 \mu \mathrm{M}$, respectively) or MBP-ExoYK81M for F-actin $(1.6 \pm 0.4 \mu \mathrm{M})$ (Supplementary Fig. 6a), were in the same range as those of many eukaryotic cytoskeletal proteins that bind along filaments $22,27-29$.

Finally, we analysed whether ExoY binding to F-actin could interfere with the regulation of filament dynamics by eukaryotic cytoskeletal proteins known to bind along the sides of filaments. We considered two key regulatory proteins, which are ubiquitous among eukaryotic cells: the Arp2/3 complex and actin-depolymerizing factor (ADF). The Arp2/3 complex, upon its activation by VCA domains of the WASP family proteins, binds to the side of a pre-existing filament where it catalyses actin filament branching $22,27,30$. ADF/cofilin proteins, present at micromolar concentrations in eukaryotic cells, bind cooperatively and preferentially to F-actin-ADP subunits along filaments $\left(K_{\mathrm{d}} \sim 0.1 \mu \mathrm{M}\right)$, severing aged filaments, and enhancing their disassembly and turnover $22,27,31$.

In experiments with the Arp2/3 complex, we performed actin polymerization assays using G-actin saturated by profilin to approach a more physiological context. As shown in Fig. 4d, the acceleration of G-actin-ATP polymerization by VCA-activated Arp2/3 (25-35 nM) was inhibited by ExoY ${ }^{\mathrm{K} 81 \mathrm{M}}$ at concentrations of $100 \mathrm{nM}$ and higher. This demonstrates that ExoY antagonizes the binding of the activated Arp $2 / 3$ complex along filaments and hence VCA-Arp2/3 regulation.

In dilution-induced F-actin-ADP disassembly assays (Fig. 4e), ExoY or ExoY $\mathrm{K}^{\mathrm{K} 1 \mathrm{M}}(100 \mathrm{nM})$ were able to completely inhibit the acceleration of filament disassembly promoted by $\mathrm{ADF}(4 \mu \mathrm{M})$ at a low ExoY:ADF ratio of 1:40. The sub-stoichiometric ratio of ExoY with respect to $\mathrm{ADF}$ and the respective $K_{\mathrm{d}}$ for $\mathrm{F}$-actin binding suggested that the complete inhibition of ADF activity by ExoY was not achieved by a direct competition for binding to F-actin. To investigate how ExoY inhibits the disassembly of F-actin mediated by ADF, we examined whether ExoY binding to F-actin imposes cooperative conformational perturbations on the F-actin structure and thus stabilizes filaments in a conformation incompatible with ADF binding and severing activity. We used the drug phalloidin, which binds with high affinity to F-actin. Compared with native filaments, phalloidin-stabilized filaments appear stiffer and exhibit an altered conformation ${ }^{32}$ that inhibits the cooperative binding and activity of ADF. To test whether ExoY imposes cooperative conformational perturbations on F-actin, we measured the binding affinity of ExoY ${ }^{\mathrm{K} 81 \mathrm{M}}$ to phalloidin-modified filaments using cosedimentation assays. For three different conformational states of F-actin: native, phalloidin-bound (Supplementary Fig. 6a), or F-actin-ADP$\mathrm{BeF}_{3}^{-}$(Fig. 4c), the affinity of MBP-ExoY $\mathrm{K}^{81 \mathrm{M}}$ for filaments remained unchanged $\left(K_{\mathrm{d}} \sim 1.6-1.8 \mu \mathrm{M}\right)$. Thus, ExoY binding does not appear to induce a particular cooperative conformational change in F-actin. Then we examined whether a pre-incubation of actin filaments with MBP-ExoY ${ }^{\mathrm{K} 81 \mathrm{M}}$ altered subsequent binding of $\mathrm{ADF}$ to F-actin. We used the low MBP-ExoY K81M:ADF ratios that antagonized ADF activity in the depolymerization assays of Fig. 4e. We found no significant change of ADF binding to F-actin at a low MBP-ExoY ${ }^{\mathrm{K} 81 \mathrm{M}}$ :ADF ratio of 1:40 and a slight decrease (about 16\%) at a 1:6.7 ratio (Supplementary Fig. 6b). This suggests that ExoY binding to F-actin antagonizes ADF depolymerizing activity by preventing its cooperative binding along actin-ADP filaments.

F-actin cell content increases upon ExoY recruitment to cables. To our knowledge, the localization of ExoY in eukaryotic cells was not previously reported and is of particular interest in light of its direct interaction with $\mathrm{F}$-actin in vitro. To avoid toxic effects of ExoY when expressed in eukaryotic cells, the catalytically inactive variant ExoY ${ }^{\mathrm{K} 81 \mathrm{M}}$ fused to AcGFP (a monomeric green fluorescent protein) was expressed in transiently transfected HeLa cells (a human cell line of epithelial origin). Co-localization of ExoY ${ }^{\mathrm{K} 81 M_{-}}$-AcGFP with F-actin was first analysed using spinning disk confocal microscopy of phalloidin-stained cells. Phalloidin was conjugated to a far-red-670 $\mathrm{nm}$ fluorophore to ensure signal 
a

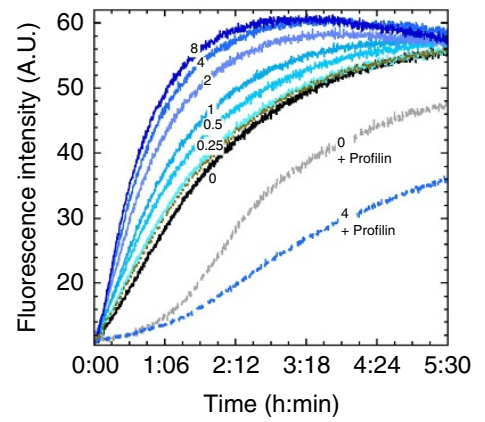

C

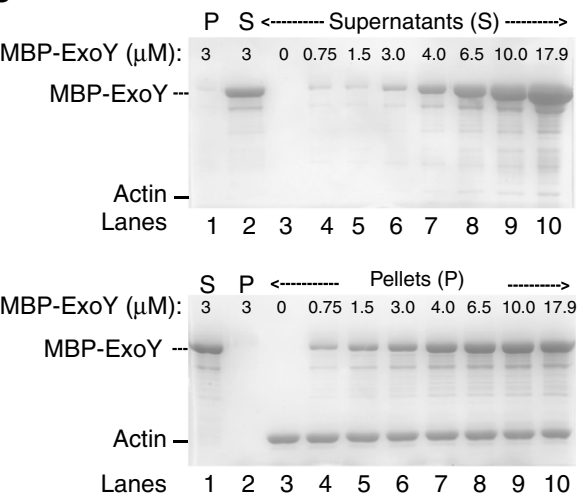

d

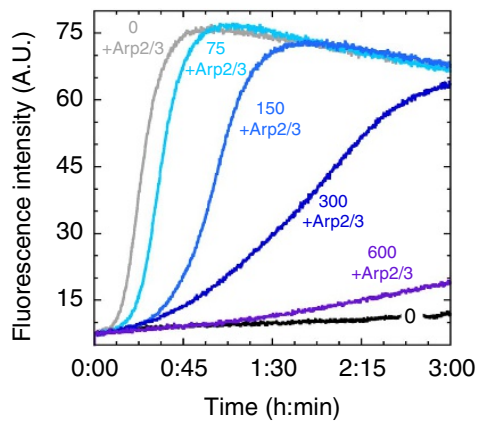

b
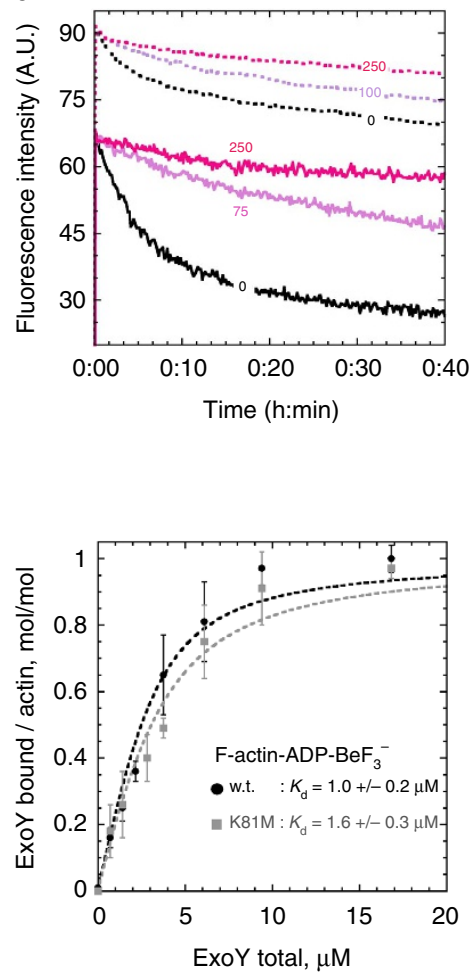

e

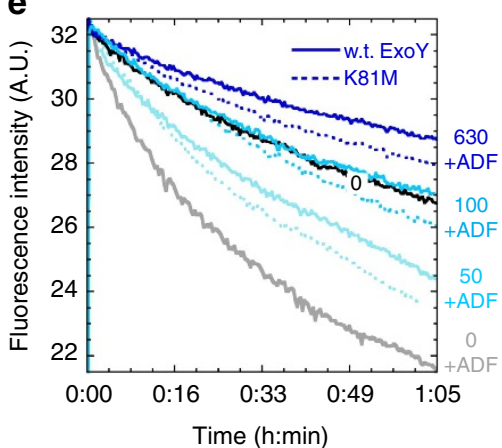

Figure 4 | ExoY association with F-actin can interfere with the regulation of filament dynamics by eukaryotic cytoskeletal proteins. (a) MBP-ExoYK81M mediated acceleration of G-actin-ATP-Mg self-assembly rate and its inhibition by profilin. Four micromolar G-actin-Mg-ATP (3\% pyrenyl labelled) was polymerized in the absence (continuous lines) or presence (dashed lines) of $12 \mu \mathrm{M}$ profilin at the indicated concentrations ( $\mu \mathrm{M}$ ) of MBP-ExoYK81M. MBP by itself ( $4 \mu \mathrm{M}$, brown) did not stimulate polymerization. (b) Exo $\mathrm{Y}^{\mathrm{K} 81 \mathrm{M}}$ binding to filaments inhibits their spontaneous disassembly kinetics from free barbedor pointed-ends. Disassembly from free barbed-ends (continuous lines): F-actin ( $2 \mu \mathrm{M}, 50 \%$ pyrenyl) at steady state was diluted to $50 \mathrm{nM}$ in the presence of 0 to $250 \mathrm{nM}$ ExoYK81M. Disassembly from pointed-ends (dotted lines): filaments with their barbed-ends capped by Gelsolin (10 $\mu \mathrm{M}$ actin, $33.3 \mathrm{nM}$ Gelsolin) at steady state were diluted to $300 \mathrm{nM}$ in the presence of 0 to $250 \mathrm{nM}$ ExoYK81M. (c) Binding affinity of MBP-fused ExoY and ExoYK81M for F-actin (MA-L) measured in high-speed cosedimentation assays. Left panels: Representative Coomassie blue stained SDS-PAGE (10\%) gel images from the supernatant $(S)$ and pellet $(P)$ fractions using $3 \mu \mathrm{M}$ of F-actin-ADP-BeF ${ }_{3}^{-}$mixed with increasing amount of MBP-ExoY $(0$ to $17.9 \mu \mathrm{M})$. Without F-actin (lanes 1 and 2) no more than 7\% of MBP-ExoY was found in the pellet. Right panel: The increasing amounts of MBP-ExoY/ExoYK81M bound to filaments were measured by densitometry, normalized and fitted to derive the equilibrium dissociation constant $\left(K_{d}\right)$ of the proteins for $\mathrm{F}_{\text {-actin-ADP-BeF }}-$. Error bars are s.e. $(n \geq 3)$. (d) Exo $\mathrm{Y}^{\mathrm{K} 81 \mathrm{M}}$ inhibits the acceleration of filament formation induced by VCA-activated Arp2/3 complex. Three micromolar G-actin-MgATP (3\% pyrenyl) was polymerized with $7.5 \mu \mathrm{M}$ profilin, $0.2 \mu \mathrm{M}$ NWASP-VCA, in the absence (black) or presence of $35 \mathrm{nM}$ Arp2/3 and 0 to $600 \mathrm{nM}$ ExoYK81M. (e) ExoY/ExoYK81M inhibits the acceleration of F-actin-ADP disassembly promoted by ADF. F-actin-ADP ( $9 \mu \mathrm{M}, 50 \%$ pyrenyl) at steady state was diluted to $4 \mu \mathrm{M}$ and preincubated for 2 min with 0 to $630 \mathrm{nM}$ ExoY (w.t., continuous lines) or ExoYK81M (dotted lines) before depolymerization assays without ADF (O nM ExoY/ExoYK81M, black) or with $4 \mu \mathrm{M}$ ADF (grey, cyan or blue curves).

separation from AcGFP. We observed the recruitment of ExoY to F-actin rich structures in particular along the plasma membrane, to ruffles and to actin cables (Fig. 5a). Calculated Pearson's correlation coefficient (PCC) of $0.57 \pm 0.15$ (mean \pm s.d.; $n>15$ cells) showed significant co-localization of ExoY ${ }^{\mathrm{K} 81 \mathrm{M}}$-AcGFP with F-actin, whereas the transfection of AcGFP alone led to a negative
PCC (Fig. 5b). To show ExoY co-localization with actin fibres, we next performed cotransfection with mCherry-Vinculin, a protein of focal adhesions. Contractile actin fibres are often connected to focal adhesion at their ends. Using total internal reflection fluorescence (TIRF) microscopy, we observed that ExoY ${ }^{\mathrm{K} 81 \mathrm{M}}$ AcGFP labelled stress fibres especially at vinculin labelled focal 
a
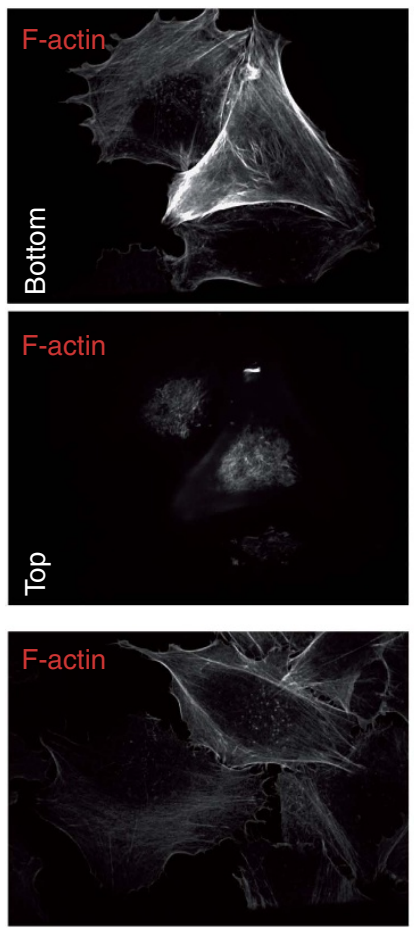

b

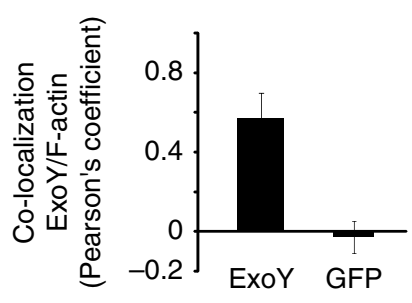

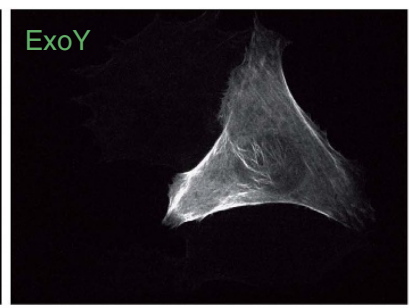
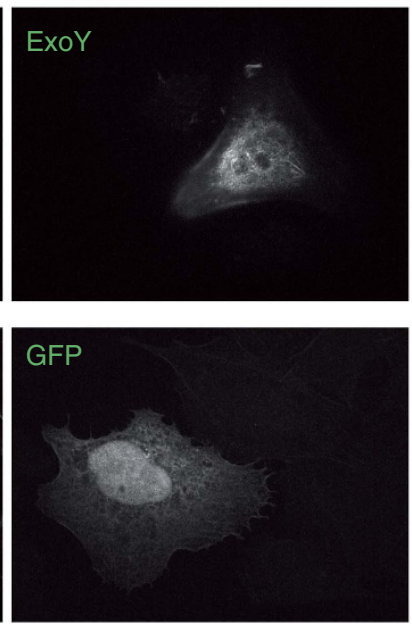

\section{c}

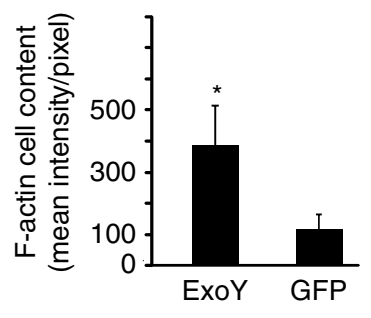

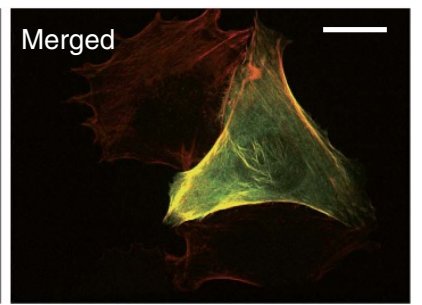
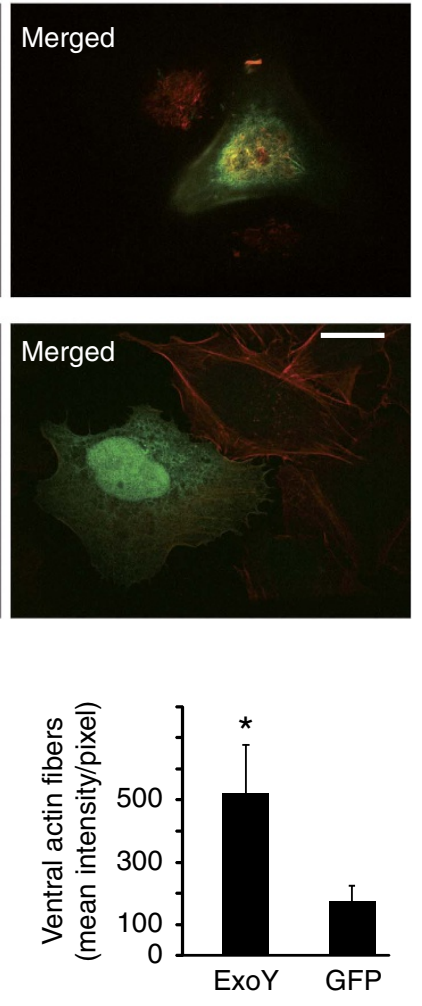

d
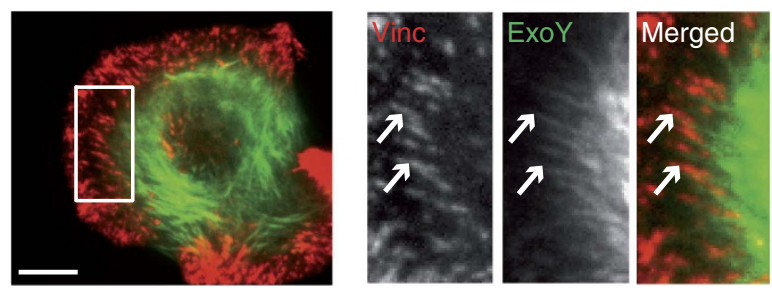

Figure 5 | ExoY co-localizes with actin cables and increases F-actin cell content. (a) Staining of F-actin (670 nm fluorescent phalloidin) in HeLa cells

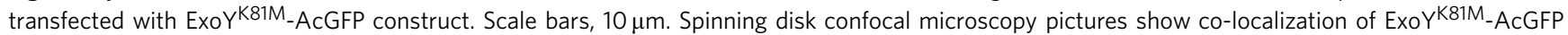
with F-actin from the bottom slices or the top ones and increased phalloidin staining in comparison to the control (AcGFP). (b) The co-localization of ExoYK81M_AcGFP with F-actin was estimated by measuring the average Pearson's correlation coefficient ( \pm s.d.; $n \geq 15$ cells) between AcGFP and 670 nm fluorescence signals in individual whole cells (without extracellular regions). (c) Quantification of F-actin within whole cells (from bottom to top slices in each cell) and of actin stress fibres at the bottom slices in ExoYK81M-AcGFP- or AcGFP-expressing cells. Data are mean fluorescent intensity per pixel \pm s.d. ( $n \geq 15$ cells; ${ }^{\star} P<0.001$; two tail Student's $t$-test). (d) TIRF pictures of HeLa cell expressing ExoYK81M-AcGFP and $m C h e r r y$-vinculin. Scale bars, $5 \mu$ m. ExoYK81M_AcGFP-labelled stress fibres terminated at vinculin-labelled focal adhesions (arrows).

adhesion (Fig. 5d), whereas GFP alone was uniformly distributed (Supplementary Fig. 7). Quantifications of phalloidin staining of spinning disk confocal microscopy pictures indicated additionally that F-actin content was increased in ExoY-expressing cells. The mean fluorescent intensities of F-actin over all section surfaces (from bottom to top within each cell), or of actin stress fibres measured at the bottom slices, were higher than in control AcGFP-expressing cells (Fig. 5c). In agreement with our biochemical analysis of ExoY in F-actin disassembly assays, these data establish that the bacterial toxin can bind to and stabilize microfilaments in host cells in the presence of myriad actin-binding regulatory proteins.

Activation of a Vibrio ExoY-like protein by actin. We further examined whether actin could activate other putative ExoY-like cyclases that are present in a number of MARTX toxins from 
a

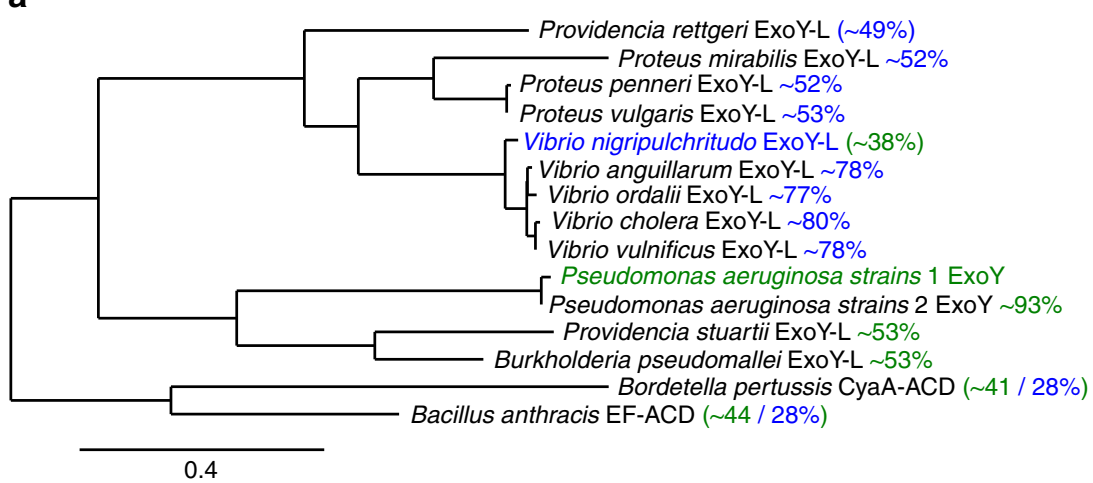

b

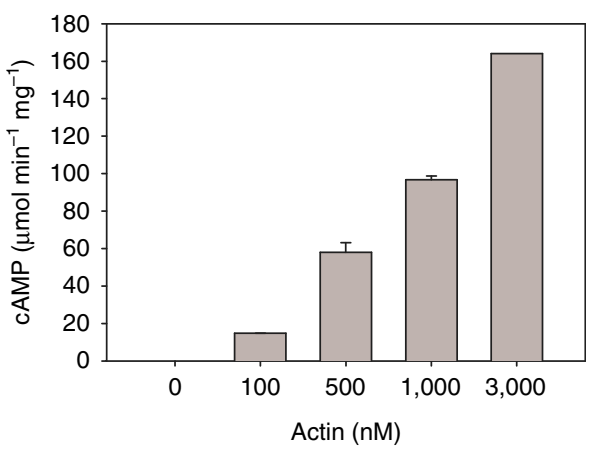

Figure 6 | The bacterial ExoY-like nucleotidyl cyclase toxin subfamily. (a) Phylogenetic tree. The amino-acid sequences of Pseudomonas aeruginosa ExoY and various ExoY-related effector domains/toxins found in several emerging Gram-negative bacterial pathogens were aligned as shown in Supplementary Fig. 8 and clustered on phylogram branches on the basis of the similarity of their amino-acid sequences using the Phylogeny.fr platform ${ }^{61}$. Calmodulin-activated edema factor and Cya Adenylate Cyclase Domains (ACD) were used as an outgroup more distantly related to ExoY-like nucleotidyl cyclase toxins to root the phylogeny. NCBI accessions of bacterial protein sequences are given in Supplementary Table 2. Pairwise sequence similarities (\%) with $P$. aeruginosa ExoY or V. nigripulchritudo ExoY-like (VnExoY-L) are given in green and blue, respectively (see Supplementary Table 2 for more details). Similarity values without parenthesis indicate the ExoY-like sequences that are the most significantly related to actin-activated ExoY or $\mathrm{VnExoY-L}$ nucleotidyl cyclases. (b) Activation of $\mathrm{VnExoY}$-L catalysed synthesis of cAMP by actin (MA-L). Reactions containing $10 \mathrm{ng} \mathrm{VnExoY-L}(3.7 \mathrm{nM}$ ) and actin at indicated concentrations were started by the addition of $2 \mathrm{mM} \mathrm{ATP}$ and incubated for $30 \mathrm{~min}$ at $30^{\circ} \mathrm{C}$. The background activity without actin was about $1 \mathrm{nmol}$ of $\mathrm{CAMP} \mathrm{min}^{-1} \mathrm{mg}^{-1}$. Error bars correspond to s.d. of two experimental replicates.

a

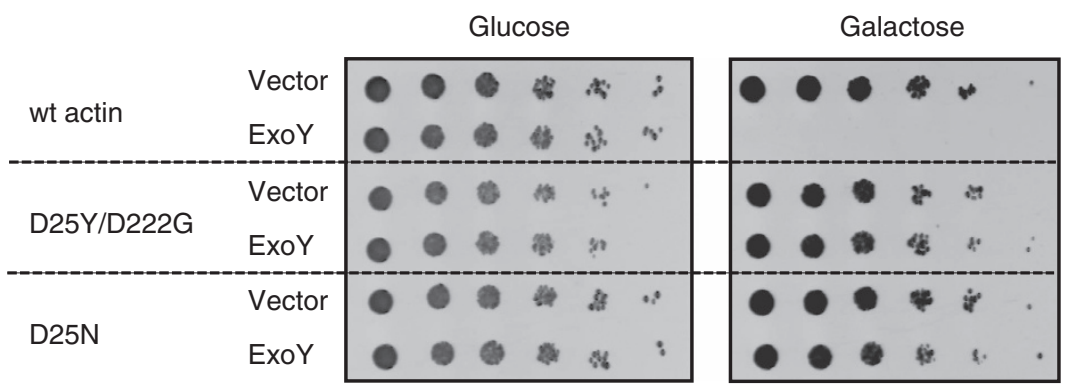

b

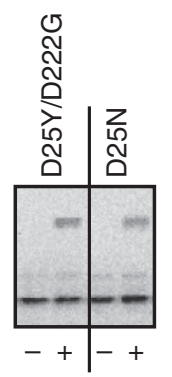

C

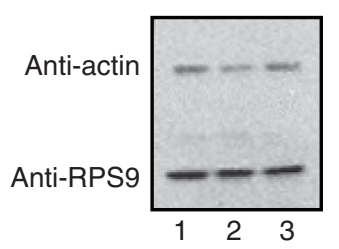

Figure 7 | Actin mutant alleles affecting the activation of ExoY. (a) Drop tests of serial dilutions of S. cerevisiae strains expressing wild-type (wt) actin (SC489), D25Y/D222G (SC690) or D25N (SC691) and p1593 for galactose-induced expression of ExoY or the corresponding vector control YEpGal555. Cell suspensions were normalized to an OD600 of 1.0 and 5-fold serial dilutions were applied as $3 \mu$ drops on SD or SG-agar plates. (b) Western blot analysis to verify expression of Myc-ExoY in SC690 and SC691 with anti-Myc or anti-RPS9 (loading control). (c) Western blot analysis to verify expression of actin in SC489 (1), SC690 (2) and SC691 (3) with anti-actin or anti-RPS9 (loading control). Uncropped images of (b,c) are shown in Supplementary Fig. 10.

pathogenic proteobacterial species present in the genera Burkholderia, Vibrio ${ }^{16}$, Providencia or Proteus (Fig. 6a). For this, we selected the ExoY-like module from the MARTX toxin encoded by the virulence-associated plasmid $\mathrm{pA}_{\mathrm{SFn} 1}$ from $V$. nigripulchritudo ${ }^{16,33}$, an emerging marine pathogen infecting farmed shrimps. The multidomain MARTX toxin is processed inside host cells into individual effector domains by an inbuilt cysteine protein domain ${ }^{34}$. The $\mathrm{N}$ - and C-terminus of the $V$. nigripulchritudo ExoY-like effector domain were chosen based on sequence alignments of $P$. aeruginosa ExoY and ExoY-like modules from several Vibrio MARTX toxins (Supplementary Fig. 8), the signature of cysteine protein domain cleavage sites present in some Vibrio ExoY-like modules and hydrophobic cluster analysis secondary structure prediction analysis. The MARTX-ExoY-like protein of $53 \mathrm{kDa}$ corresponding to residues Y3412 to L3872 of Uniprot reference F0V1C5 was termed here VnExoY-L. The protein carrying a C-terminal Flag-His tag (VnExoY-L-FH) was purified and tested for its adenylate cyclase activity in the presence and absence of actin. Figure $6 \mathrm{~b}$ shows that VnExoY-L displayed a potent adenylate cyclase activity in the presence of actin, which stimulates the enzymatic activity more than 10,000 fold. In contrast to $P$. aeruginosa ExoY, VnExoY-L did not exhibit any cGMP synthesizing activity. We conclude that actin may be a common activator of the various ExoY-like cyclase modules.

Identification of actin mutants that fail to activate ExoY. To further delineate the molecular mechanism of activation of ExoY by actin, we attempted to identify actin mutants with impaired ability to activate ExoY. For this purpose, we used a recently developed yeast genetic screen, in which the wild-type actin of $S$. cerevisiae is replaced by actin variants expressed from a plasmid ${ }^{35}$. S. cerevisiae contains a single actin gene (act1), which can be deleted provided the strain harbours a plasmid (with an URA3 marker) carrying a complementary copy of wild-type actin (S. cerevisiae act1::LEU2 + pACT1 [URA3]). This recombinant strain was then transformed with a pool of plasmids carrying the HIS3 auxotrophic marker and expressing actin variants generated by in vitro mutagenesis (see Methods). Subsequently, the URA3-containing plasmid was eliminated (by selection on 5 -fluoroorotic acid containing medium) $)^{36}$ and the 
resulting cells, therefore, expressed only the actin variants encoded by the HIS3-plasmid ${ }^{35}$. These cells were transformed with a plasmid (p1654) expressing ExoY (Myc-ExoY-NanoLuc) under the control of the galactose-inducible GAL1 promoter and cells that tolerated ExoY expression were isolated. Twenty-one ExoY-resistant colonies (with unimpaired ExoY expression levels) were selected and found to harbour two different actin mutant alleles: 14 mutants had a double substitution, D25Y and D222G, and 7 had a single modification D25N. Figure 7a compares growth of S. cerevisiae strains expressing wild-type actin (SC489), mutant D25Y/D222G (SC690) or mutant D25N (SC691) and ExoY in drop tests of sequentially diluted cultures. Whereas ExoY expression (that is, in the presence of galactose) totally inhibited the growth of the wild-type strain, it did not affect the growth of the yeast cells harbouring either one of the two actin mutants. We verified ExoY expression in the actin mutant strains by western blots with anti-Myc antibodies (Fig. 7b). Both actin variants were similarly expressed (Fig. 7c) and supported growth of $S$. cerevisiae: the double mutant grew slightly more slowly in SD minimal medium as compared with the wild type and the single mutant (doubling time $3 \mathrm{~h}$ versus $2.5 \mathrm{~h}$, respectively) and was slightly affected under different stress conditions tested: at 15 or $37^{\circ} \mathrm{C}$ or in the presence of $1 \mathrm{M} \mathrm{NaCl}$ (Supplementary Fig. 9). Crude extracts of the different $S$. cerevisiae strains were then prepared and tested for their ability to activate ExoY in vitro. While extracts from wild-type cells strongly stimulated ExoY, no activity of ExoY was detected in extracts from yeasts expressing the actin mutants (Table 1). In addition, we found that the actin mutations D25Y/D222G or D25N also largely impaired the activation of the Vibrio enzyme Vn-ExoY in vitro (Table 1).

\section{Discussion}

Bacterial toxins that use substrates not unique to eukaryotic organisms need to be kept inactive within the bacterial pathogen in order to prevent detrimental effects to the native host. Once they enter the eukaryotic host cell, the toxin is usually activated by a host cell cofactor that typically represents a specific and abundant protein/marker of their hosts. Actin fits these criteria perfectly well: actin is absent from bacteria, found in essentially all eukaryotic cells where it is one of the most abundant proteins, and despite evolutionary separation by billions of years, S. cerevisiae and human actin share $87 \%$ amino-acid sequence identity. These features make actin also a frequent target of bacterial toxins that can affect the polymerization state of actin in different ways by introducing modifications, such as ADPribosylation at different position or crosslinking (for reviews see refs 37,38$)$. The provoked rearrangements have a profound effect on the cytoskeleton of the host cells and affect their response to bacterial invasion.

Here we show that actin is a potent activator of a group of bacterial toxins that are homologous to the $P$. aeruginosa ExoY effector and that display nucleotidyl cyclase activities with different substrate selectivity.

We demonstrate that mammalian actin is able to stimulate ExoY's adenylate and guanylate cyclase activities more than 10,000 fold to reach specific activities (in optimum conditions) of about 120 and $900 \mu \mathrm{mol} \mathrm{min}^{-1} \mathrm{mg}^{-1}$ for cAMP and cGMP synthesis, respectively (Fig. $3 \mathrm{a}$ ). The higher guanylate cyclase activity as compared with the adenylate cyclase one is in agreement with the preferential accumulation of cGMP over cAMP observed in vivo ${ }^{7,8}$. The corresponding kcat for cGMP synthesis is approaching $1,000 \mathrm{~s}^{-1}$ and, therefore, within the same order of magnitude as the catalytic rates measured for cAMP synthesis for the related cyclase toxins CyaA or edema factor, when activated by calmodulin, their common eukaryotic activator $^{39,40}$

Using a yeast genetic screen (Fig. 7), we further identified an actin mutation (D25N) that blunts actin's ability to activate ExoY. D25 in actin subdomain 1 is a charged residue solvent-exposed in F-actin and can thus be part of the contact interface of F-actinbinding proteins ${ }^{41}$. These data not only confirm that actin is an activator of ExoY but demonstrate that actin is the only activator of ExoY present in yeast. We can thus exclude the possibility that a contaminant present in the actin preparations could be responsible for activation of ExoY in our in vitro assays.

Our results support the view that polymerization of G-actin into F-actin is critical for maximum activation of ExoY. First, the maximal activation of ExoY by actin-ATP or actin-ADP was correlated with F-actin formation in each nucleotide state (Fig. 3b). Second, ExoY activation by actin was strongly antagonized by different G-actin-binding proteins, such as profilin, or a T $\beta 4$-derivative protein with similar sequestering activity as $\mathrm{T} \beta 4$ (chim2-T $\beta 4$ ), or by latrunculin A that prevents actin polymerization (Fig. 3c). Finally, ExoY binds along naked filaments with a low micromolar affinity $\left(K_{\mathrm{d}}\right.$ of about $1 \pm 0.2 \mu \mathrm{M}$, Fig. 4c), which should allow efficient competition in vivo with many eukaryotic cytoskeletal side-binding proteins that also bind along filaments with low micromolar affinity ${ }^{27-29}$. The co-localization of ExoY-GFP with F-actin rich structures confirmed that ExoY indeed associates with actin filaments within cells (Fig. 5).

ExoY thus represents to our knowledge the first example of a bacterial toxin that is activated by F-actin. G-actin has been shown previously to activate a bacterial toxin secreted by the T3SS namely YopO/YpkA, a multidomain protein from Yersinia species (Y. enterocolitica and Y. pseudotuberculosis, respectively), which is involved in the disruption of the actin cytoskeleton ${ }^{42,43}$. In contrast, $P$. aeruginosa ExoY binding to F-actin inhibits the spontaneous or regulated dynamics of F-actin disassembly in vitro (Fig. 4b,e) increasing the microfilament content in transfected cells (Fig. 5). YopO binding with an actin monomer induces autophosphorylation and activation of its $\mathrm{N}$-terminal serine/threonine kinase domain ${ }^{43}$. In the YopO:G-actin complex, the bound actin is sequestered from polymerization and used subsequently as bait to recruit, phosphorylate and thus misregulate various host actin-regulating proteins ${ }^{44}$. The mechanisms of activation of ExoY and YopO by F- and G-actin, respectively, are, therefore, likely different.

While most of the ExoY related toxicity in infected cells depends on its nucleotidyl cyclase activity, its direct binding to actin filaments could additionally alter normal host cell homeostasis. We showed that in vitro (Fig. 4e), ExoY (as low as

Table 1 | Activation of ExoY or VnExoY-L by S. cerevisiae extracts expressing wild-type or mutant actin.

\begin{tabular}{|c|c|c|c|c|}
\hline $\begin{array}{l}\text { ExoY-catalysed synthesis of cGMP }\left(\mathrm{nmol} \mathrm{min}^{-1} \mathrm{mg}^{-1}\right) \\
\text { VnExoY-L-catalysed synthesis of cAMP }\left(\mathrm{nmol} \mathrm{min}^{-1} \mathrm{mg}^{-1}\right)\end{array}$ & $\begin{array}{l}<5 \\
<5\end{array}$ & $\begin{array}{l}2,950 \pm 330 \\
2,800 \pm 210\end{array}$ & $\begin{array}{l}<5 \\
<5\end{array}$ & $\begin{array}{c}<5 \\
19 \pm 8\end{array}$ \\
\hline
\end{tabular}


$50 \mathrm{nM}$ ) can antagonize the cooperative activity of ADF at submolar ratios of ExoY with respect to the regulatory cytoskeletal side-binding protein. Even though ExoY may be present at lower concentrations in host cells, its binding along actin filaments might nevertheless contribute to destabilizing precise spatial and temporal regulation of actin dynamics in eukaryotic cells. Huber et al. ${ }^{15}$ have recently observed that at $3 \mathrm{~h}$ post-infection, a $P$. aeruginosa T3SS effector mutant strain expressing only ExoY showed slightly increased human endothelial cell spreading, suggesting a stabilization of the actin cytoskeleton. It will thus be interesting to examine in more details, the actin cytoskeleton dynamics of host cells upon infection with bacteria expressing catalytically inactive ExoY or ExoY-like proteins alone or together with other toxins affecting actin cytoskeleton regulation (ExoS, ExoT from $P$. aeruginosa, actin cross-linking (ACD) or RhoGTPase inactivation domain (RID) from various MARTX toxins of the Vibrio genus ${ }^{16}$ ). Given that ExoS and ExoT disrupt actin filaments, cytotoxicity of ExoY might be self-limited by the interplay between $P$. aeruginosa T3SS toxins. Such an interplay between ExoY and ExoS or ExoT activities via the actin cytoskeleton integrity may explain why a mutant strain of $P$. aeruginosa injecting only ExoY as T3SS effector was found more potent for inducing high cAMP levels in infected human endothelial cells than the wild-type or mutant strains expressing all three T3SS toxins or ExoY with either ExoS or ExoT, respectively ${ }^{15}$.

ExoY-like modules are frequently found among the effector domains of MARTX toxins in multiple bacterial species of the Vibrio genus ${ }^{16}$, which represent emerging human or animal pathogens. In addition, ExoY-like proteins can be found in various other Gram-negative pathogenic bacteria from the genus Providencia, Burkholderia or Proteus (Fig. 6a). Here we showed that VnExoY-L, a rather distantly related ExoY-like module from $V$. nigripulchritudo, was also strongly stimulated (more than 10,000 fold) by actin and efficiently synthesized cAMP but not cGMP (Fig. 6b). The lack of guanylate cyclase activity is in agreement with the results obtained with the V. vulnificus ExoYlike module ${ }^{16}$, a close homologue of VnExoY-L ( $>75 \%$ sequence similarity, Fig. 6a and Supplementary Table 2), and may thus reflect a more general difference regarding the nucleotide substrate specificities between the $P$. aeruginosa ExoY and other ExoY-like proteins found in MARTX toxins similar to those present in the Vibrio genus (Fig. 6a and Supplementary Fig. 8).

Actin thus represents a common eukaryotic activator for several exoenzymes (Fig. 6a) within the class II adenylyl cyclase toxin family (described in ref. 19). We propose the term actinactivated nucleotidyl cyclase toxins to describe this particular subfamily.

\section{Methods}

Strains and growth conditions. Strains, plasmids and primers are described in Supplementary table 1.

E. coli strains were grown in lysogeny broth. Ampicillin $\left(100 \mu \mathrm{g} \mathrm{ml}^{-1}\right)$ was added for plasmid maintenance in E. coli. S. cerevisiae strains were grown in yeast extract peptone dextrose or yeast extract peptone galactose media or in minimal medium containing yeast nitrogene base without amino acids (Difco) containing galactose (SG) or glucose (SD) supplemented with uracil, histidine, tryptophane and/or adenine if required. Glucose or galactose was present at $2 \%$. Hygromycin (Sigma) was present at $200 \mu \mathrm{g} \mathrm{ml}^{-1}$, to maintain plasmids in yeast. S. cerevisiae strains were transformed using the lithium-acetate method ${ }^{45}$.

The plasmid for expression of HF-ExoY under control of the arabinoseinducible promoter $\mathrm{P}_{\text {ara }}(\mathrm{pUM} 447)$ was cloned as follows: Primers UM248 and UM254 were used to PCR-amplify exoY from P. aeruginosa PAO1 chromosomal DNA. The EcoRI, XbaI digested fragment was used to replace the EcoRI/XbaI fragment of pUM407. pUM449 for arabinose-inducible expression of ExoY-FH was constructed by PCR-amplifying exoY using UM245 and UM250, digestion with EcoRI and XhoI and replacing the EcoRI/XhoI fragment from pUM407. Protein expression levels were low. We, therefore, constructed a plasmid expressing ExoY-FH from $\lambda \mathrm{P}_{L}$ controlled by the temperature sensitive cI repressor (cI857),
pUM460. For this, the fragment coding for ExoY-FH from pUM449, was PCR-amplified using primer UM254 and UM255 and cloned as NcoI/XbaI fragment into the same sites of plasmid pTRCAG.

pUM483 and pUM482 for expression of TAP-tagged or HA-tagged ExoY, respectively in S. cerevisiae were cloned using Gateway technology. The entry vector (pUM478) was created in pDONR221 (Invitrogen) by introducing a PCR fragment amplified with primers UM282 and 283 from template pUM449. The fragment coding for ExoY was transferred by in vitro recombination from pUM478 into to the destination vectors pAG415GAL-ccdB-TAP and pAG415GAL-ccdBHA (ref. 46). The LEU2 marker was then exchanged to a hygromycin resistance cassette by in vivo recombination as follows: The 6.8 or $7.6 \mathrm{~kb}$ fragment obtained after MunI digestion of pUM483 or pUM482, respectively was isolated from agarose gel and transformed into $S$. cerevisiae together with the hygromycin resistance cassette which was PCR amplified from pAG32 using primer UM302 and UM303 to yield pUM484 (ExoY-TAP, Hygromycin ${ }^{\mathrm{R}}$ ) and pUM485 (ExoYHA, Hygromycin ${ }^{\mathrm{R}}$ ), respectively.

For the construction of clones expressing the ExoY ${ }^{\mathrm{K} 81 \mathrm{M}}$ mutant, two PCR fragments were amplified using pUM451 as template: PCR1 was performed with primers UM316 and UM318, and PCR2 was performed with primers UM319 and UM317. The outside primers UM316 and UM317 and equimolar amounts of PCR fragments 1 and 2 were used to perform overlapping PCR. The obtained PCR fragment was directly placed into pGEM-T Easy (Promega) by TA cloning. A sequence verified clone (pUM492) was used as source for the $155 \mathrm{bp} \mathrm{SphI/SalI}$ fragment containing the mutated sequence part of exoY to replace the SphI/SalI fragment from pUM484 and pUM485 yielding pUM497 (ExoYK81M-TAP) and pUM498 (ExoY K81M-HA), respectively.

pUM503 expressing ExoY K81M $-\mathrm{FH}$ under $\lambda \mathrm{P}_{L}$-cI857 was created by exchanging the SacII/SphI fragment from pUM460 by that of pUM497. pUM518 for the expression of ExoY ${ }^{\mathrm{K} 81 \mathrm{M}}$ fused to the N-terminus of AcGFP in mammalian cells was created by insertion of a NheI/XhoI digested PCR fragment that was amplified from pUM503 using primer UM345 and UM246 into pAcGFP-N1.

pUM522 for the expression of Vn-ExoY-L-FH from $\lambda \mathrm{P}_{L}$ controlled by the temperature sensitive cI repressor (cI857) was constructed by replacing the NcoI/KpnI fragment expressing ExoY from pUM460 by the PCR fragment that was amplified from $V$. nigripulchritudo DNA using primer UM355 and UM356. pEA11 and pEA12 for the expression of His-MBP-ExoY-ST or His-MBPExoYK81M_ST under control of the $\mathrm{P}_{t a c}$ promoter were constructed as follows: Primers UM350 and UM246 were used to PCR-amplify exoY or the mutant gene from pUM445 or pUM502, respectively. The BglII, XhoI digested fragments were inserted into a modified pGEX-6-P1 (ref. 47) digested with BamHI and XhoI.

p1593 for the expression of ExoY with a N-terminal Myc-tag in yeast was created by insertion of a Xhol/KpnI digested PCR fragment that was amplified from pUM485 using primer 1259 and 1260 into YEpGal555 (ref. 35). ExoY expressed from p1595 was C-terminally fused to NanoLuciferase to allow quantification of expression. The fragment coding for NanoLuc was PCR-amplified from pNL1.1 (Promega) using primers 1261 and 1262 and fused to the exoY gene in p1593 using the KpnI and NheI sites.

p1559 was created by replacing the cassette coding for $\beta$-lactamase (Bla) in YEpGal555 by the kanamycin resistance cassette (KmR) from pVK-3. For this purpose a NcoI site was created $5^{\prime}$ of the bla gene of YEpGal555 by site-directed mutagenesis using primers 1217 and 1218. The NcoI/AhdI digested vector was blunted and ligated with the PstI digested and blunt ended fragment from pVK-3 coding for $\mathrm{kmR}$. The SacI/NheI fragment from p1595 coding for ExoY was then inserted into this vector to yield p1654.

Plasmid p1387 was used for random mutagenesis of S. cerevisiae act1 and was created from p1182 by removing the ClaI site located within act1 to construct a plasmid with unique ClaI and SalI sites flanking the gene's second exon coding for amino acid 4 to the C'end of Act1.

Protein purification. ExoY-FH and VnExoY-L-FH were purified by nickel affinity chromatography under denaturing conditions (in the presence of $8 \mathrm{M}$ urea) from the non-soluble protein fraction obtained from 1 liter cultures of E. coli BLR (pUM460) or (pUM522), respectively. Proteins were expressed from the $\lambda \mathrm{P}_{L}$ promoter controlled by the temperature sensitive $\mathrm{cI}$ repressor (cI857), which was induced by shifting the temperature from 30 to $42{ }^{\circ} \mathrm{C}$. Proteins were renatured by dialysis into $25 \mathrm{mM}$ Tris- $\mathrm{HCl} \mathrm{pH} 9.0,500 \mathrm{mM} \mathrm{NaCl}, 10 \%$ glycerol, $1 \mathrm{mM} \mathrm{1,4-}$ dithiothreitol (DTT) for ExoY-FH and $50 \mathrm{mM}$ Tris- $\mathrm{HCl} \mathrm{pH} 8.0,200 \mathrm{mM} \mathrm{NaCl}$, $10 \%$ glycerol, $1 \mathrm{mM}$ DTT for VnExoY-FH. HF-ExoY was purified from the soluble fraction obtained from 0.51 cultures of MG1655 (pUM447) that were grown at $30{ }^{\circ} \mathrm{C}$.

The fusion constructs of ExoY/ExoY ${ }^{\mathrm{K} 81 \mathrm{M}}$ with an N-terminal maltose-binding protein (MBP), designed as follows: (His-tag)-(MBP)-(PreScission-site)-(ExoY/ ExoY $\left.{ }^{\mathrm{K} 81 \mathrm{M}}\right)$-(Strep-tagII) and referred in the text as MBP-ExoY/ExoYK81M_ST, or their truncated forms (ExoY/ExoY ${ }^{\text {K81M }}$-ST) were purified under non-denaturing conditions successively from HisTrap, StrepTrap, and Superdex $20016^{\star} 60$ columns using standard protocols. The His-tag-MBP fusion was either cleaved or not using PreScission protease before the StrepTrap purification step. Proteins were stored in $25 \mathrm{mM}$ Tris- $\mathrm{HCl} \mathrm{pH} 8.8,150 \mathrm{mM} \mathrm{KCl}, 3 \mathrm{mM}\left(\mathrm{NH}_{4}\right)_{2} \mathrm{SO}_{4}, 0.5 \%$ Glycerol, $1 \mathrm{mM}$ 
DTT. His-tagged MBP by itself had no effect alone on actin polymerization (Fig. 4a) or depolymerization rates.

Rabbit skeletal muscle alpha-actin was purified in our laboratory (referred as MA-L) using several cycles of polymerization and depolymerization as previously

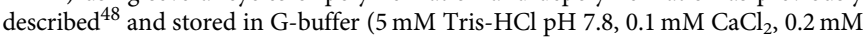
ATP, $1 \mathrm{mM}$ DTT). The purity of MA-L was estimated to be $>95 \%$ according to analysis on denaturating SDS-PAGE gels. Functionality was controlled by several cycles of polymerization/depolymerization and by verifying that the measured actin concentrations of our samples fit the known critical concentration values of a fully functional and highly pure actin. ADP-actin was prepared by treatment of ATP-G-actin with hexokinase and glucose ${ }^{49}$.

Recombinant profilin I from mouse, chimera 2 of Thymosin- $\beta 4$ and Drosophila ciboulot first $\beta$-Thymosin domain (chim2-T $\beta 4$ referred as $\mathrm{CH} 2$ in ref. 25), full-length human gelsolin, VCA domain of human neural Wiskott-Aldrich syndrome protein (N-WASP), the Arp2/3 complex from bovine brain or Spectrin-actin seeds from human erythrocytes were purified as described previously ${ }^{25,50-52}$.

\begin{abstract}
Affinity purification. S. cerevisiae cells expressing ExoY ${ }^{\mathrm{K} 81 \mathrm{M}}$-TAP [TAP-tag as follows: Calmodulin-binding peptide separated by TEV protease cleavage site from the IgG-binding domain (amino acids 80-312 of protein A from Staphylococcus aureus, P02976] from pUM497 or ExoY ${ }^{\mathrm{K}^{1 M}}$-HA [3 tandem HA (Human influenza hemagglutinin) tags] from pUM498 as mock control were grown in $2 \mathrm{~L}$ yeast extract peptone galactose at $30^{\circ} \mathrm{C}$. One step purification using Dynabeads M-270 Epoxy (Invitrogen) conjugated to rabbit IgG (Sigma, Ref. I5006) were performed according to ref. 53. One half of the methanol/chloroform precipitated protein was analysed by PAGE followed by staining with Bio-Safe Coomassie G-250 (BIO-RAD) followed by silver staining (Pierce). The second half was directly digested by trypsin and analysed by LC-MS/MS analysis at the proteomic facility of the Paris Descartes University (3P5) according to the details specified below. The raw data were analysed by MaxQuant 1.3.0.5. software (ref. 54) for protein identification and quantitative estimation of the specific enrichment of proteins in the experimental sample as compared with the control.
\end{abstract}

LC-MS/MS analysis. Proteomics analyses were realized at the 3P5 proteomics facility, Université Paris Descartes, Sorbonne Paris Cité, Institut Cochin, Paris as previously described ${ }^{55}$. Briefly: LC-MS protein analysis: peptides from Trypsin-digested extracts were concentrated, washed and analysed using a reverse phase C18 column on an u3000 nanoHPLC hyphenated to a Linear Trap Quadrupole-Orbitrap mass spectrometer (all from Thermo). LTQ MS/MS CID spectra were acquired from up to 20 most abundant ions detected in the Orbitrap MS scan. Proteome discoverer 1.3 (Thermo) with Mascot (matrixscience ${ }^{56}$ ) was used for protein identification. Separate analyses were compared using the MyPROMS software ${ }^{57}$.

Pull-downs and cosedimentation assays. Actin (MA-L) was converted to $\mathrm{Mg}$ ATP actin and allowed to polymerize to steady state at $20 \mu \mathrm{M}$ for $2 \mathrm{~h}$ at room temperature (Fig. 2a) or prevented from polymerization by the addition of latrunculin A to $30 \mu \mathrm{M}$ (Fig. 2b), then diluted fivefold in binding buffer $(50 \mathrm{mM}$ Na-phosphate pH 8.0, $300 \mathrm{mM} \mathrm{NaCl}, 25 \mathrm{mM}$ imidazole, $5 \mathrm{mM}$ ATP, $20 \mathrm{mM}$ $\mathrm{MgCl}_{2}$, complete EDTA-free protease inhibitor cocktail (Roche)) and added to $7.5 \mu \mathrm{l} \mathrm{Ni-NTA}$ agarose beads. Equimolar amounts $(12 \mu \mathrm{g})$ of ExoY-FH or the corresponding buffer were added and binding was allowed in batch for $1 \mathrm{~h}$ at $4{ }^{\circ} \mathrm{C}$ rotating in Durapore filter units (Millipore). Samples were washed three times with $350 \mu \mathrm{l}$ wash buffer 20 (as binding buffer but containing $20 \mathrm{mM}$ imidazole and $0.5 \mathrm{mM} \mathrm{ATP}$, and $6 \mu \mathrm{M}$ latrunculin A for samples containing G-actin) and once in wash buffer 40 (as wash buffer 20 but containing $40 \mathrm{mM}$ imidazole). Elution of bound proteins was performed by adding a $55 \mu$ l aliquot of hot $\left(95^{\circ} \mathrm{C}\right)$ SDS sample buffer (NuPage, Invitrogen). After $15 \mathrm{~min}$ of incubation at $65^{\circ} \mathrm{C}$, the eluate was collected by centrifugation at $10,000 \mathrm{~g}$ for $1 \mathrm{~min}$. A rinse of the beads was performed by adding $50 \mu \mathrm{l}$ of SDS sample buffer at $95^{\circ} \mathrm{C}$ and centrifuging for $1 \mathrm{~min}$ at $10,000 \mathrm{~g}$. Eluates were pooled into the 'bound fraction' (elu). Corresponding amounts of bound (elu) and unbound (flow through, $\mathrm{fth}$ ) fractions were analysed to allow direct comparability. Aliquots ( $10 \%$ of the total sample volume) of unbound or bound fraction and the corresponding inputs were analysed by SDS/PAGE on $4-12 \%$ NuPAGE Bis-Tris gels (Invitrogen) in NuPAGE MES SDS running buffer and the gel was stained with Bio-Safe Coomassie stain.

F-actin cosedimentation assays (Fig. 2c) were performed using $\alpha$-actin (MA-99) according to the instructions of Cytokeleton, Inc supplied with the 'Actin binding Protein Biochem Kit Muscle actin' with the here specified modifications. Twenty microlitres of a $48 \mu \mathrm{M}$ actin (MA-99) solution in G'-buffer ( $5 \mathrm{mM}$ Tris- $\mathrm{HCl} \mathrm{pH} 8.0$, $0.2 \mathrm{mM} \mathrm{CaCl}_{2}, 0.5 \mathrm{mM}$ DTT, $0.2 \mathrm{mM}$ ATP, $5 \%$ glycerol) were thawed on ice, then added to $50 \mu \mathrm{l} 50 \mathrm{mM}$ bis-tris propane $\mathrm{pH} 9.5$ and allowed to sit on ice for $40 \mathrm{~min}$ before polymerization was induced according to the protocol. These specific buffer conditions were chosen to allow maximum solubility of ExoY and were shown in our experiment to be compatible with polymerization of actin. Thirty microlitres of polymerized F-actin stock solution were combined with $20 \mu \mathrm{l}$ of a solution containing $12 \mu \mathrm{g}$ ExoY-FH in $50 \mathrm{mM}$ bis-tris propane $\mathrm{pH}$ 9.5, $270 \mathrm{mM} \mathrm{NaCl}, 2 \mathrm{mM}$ $\mathrm{DTT}$ and $1 \times$ polymerization buffer from which non-soluble aggregates had been removed previously by centrifugation at 54,000 r.p.m. in a TL55 rotor (Beckmann) at $18^{\circ} \mathrm{C}$ for $1 \mathrm{~h}$. This mixture as well as controls containing only actin or only ExoY and the corresponding buffers present in the experiment were incubated at room temperature for $30 \mathrm{~min}$ and centrifuged at 54,000 r.p.m. for $90 \mathrm{~min}$ at $18^{\circ} \mathrm{C}$. Aliquots of supernatant and resuspended pellet fraction corresponding to $15 \%$ of the total samples were analysed by SDS-PAGE.

To measure the equilibrium dissociation constant $\left(K_{\mathrm{d}}\right)$ of the ExoY:F-actin complex by cosedimentation assays we used MBP-ExoY/ExoY ${ }^{\mathrm{K} 81 \mathrm{M}}$-ST and muscle $\alpha$-actin (MA-L) (Fig. 4c, Supplementary Fig. 6b). MBP-ExoY/ExoY ${ }^{\text {K81M }}$-ST should provide a reliable estimate of ExoY affinity for F-actin because these constructs perform similarily as ExoY/ExoY ${ }^{\mathrm{K} 81 \mathrm{M}_{-} \mathrm{ST}}$ in depolymerization assays. MBP-ExoY/ExoY ${ }^{\mathrm{K}^{81}}$-ST allowed separating and quantifying unambiguously by densitometry the fraction of the bound toxin at $88.9 \mathrm{kDa}$ from actin at $42 \mathrm{kDa}$ on SDS-PAGE gels, while ExoY-ST (M.W. of $43 \mathrm{kDa}$ ) was migrating too close to actin (M.W. of $42 \mathrm{kDa}$ ). No bundling activity was observed for ExoY in low-speed pelleting assays with $\mathrm{F}$-actin. Three micromolar of $\mathrm{F}$-actin-ADP-BeF${ }_{3}^{-}$at steady state in ( $5 \mathrm{mM}$ Tris- $\mathrm{HCl} \mathrm{pH} \mathrm{7.8,} 0.1 \mathrm{M} \mathrm{KCl}, 2 \mathrm{mM} \mathrm{MgCl} 2,1 \mathrm{mM}$ DTT, $5 \mathrm{mM}$ ADP, $1.2 \mathrm{mM} \mathrm{NaF}, 0.6 \mathrm{mM} \mathrm{BeCl}_{2}$ ) (Fig. 4c) or of F-actin polymerized overnight to steady state in ( $5 \mathrm{mM}$ Tris- $\mathrm{HCl} \mathrm{pH} 7.8,0.1 \mathrm{M} \mathrm{KCl}, 2 \mathrm{mM} \mathrm{MgCl} 2,1 \mathrm{mM}$ DTT, $5 \mathrm{mM}$ ATP, $2 \mathrm{mM}$ GTP) with or without $6 \mu \mathrm{M}$ phalloidin (Supplementary Fig. $6 \mathrm{~b}$ ) was mixed for $1 \mathrm{~h}$ with increasing amounts of MBP-ExoY/ExoY ${ }^{\mathrm{K}^{81 \mathrm{M}}}-\mathrm{ST}$ (0 to $\left.17.9 \mu \mathrm{M}\right)$. The unpolymerized ( $\mathrm{S}$, supernatant) and polymerized ( $\mathrm{P}$, pellet) fractions were separated by an ultracentrifugation for $30 \mathrm{~min}$ at $200,000 \mathrm{~g}$, resolved by $10 / 15 \%$ SDS-PAGE and detected by coomassie blue staining. The ExoY-bound fraction was quantified by densitometry using the ImageJ software and this ExoY-bound concentration normalized by the F-actin concentration was plotted versus ExoY concentration. The following equation was used to fit the data, in which [F0] is the initial concentration of F-actin, [E0] the total concentration of ExoY in each measurement, and $K_{\mathrm{d}}$ the equilibrium dissociation constant. The fraction $\mathrm{R}$ of ExoY bound to F-actin is as follows:

$$
R=\frac{K_{\mathrm{d}}+[E 0]+[F 0]-\sqrt{\left(K_{\mathrm{d}}+[E 0]+[F 0]\right)^{2}-4 *[E 0] *[F 0]}}{2 *[F 0]}
$$

Quantification of cAMP or cGMP synthesis in vitro. cAMP and cGMP synthesis were measured in $50 \mu \mathrm{l}$ reactions containing $50 \mathrm{mM}$ Tris- $\mathrm{HCl} \mathrm{pH} \mathrm{8.0,7.5} \mathrm{mM}$ $\mathrm{MgCl}_{2}, 0.5 \mathrm{mg} \mathrm{ml}^{-1} \mathrm{BSA}, 200 \mathrm{mM} \mathrm{NaCl}, 1 \mathrm{mM}$ DTT, $2 \mathrm{mM}$ ATP or GTP spiked with $0.1 \mu \mathrm{Ci}$ of $\left[\alpha_{-}{ }^{33} \mathrm{P}\right]$ ATP or $\left[\alpha^{-33} \mathrm{P}\right]$ GTP, respectively, ExoY and indicated amounts of $\mathrm{HeLa} / \mathrm{S}$. cerevisiae cell extracts or purified actin (collectively termed activator). Reactions for Figs 1a and 3a contained in addition $0.02 \%$ triton X-100, $0.1 \mathrm{mM} \mathrm{CaCl}_{2}$ and were lacking $\mathrm{NaCl}$. Reactions were performed at $30^{\circ} \mathrm{C}$ and were started by adding nucleotide substrate after a 5-10 min preincubation of ExoY plus activator. Under the conditions used, reactions were time linear for at least $20 \mathrm{~min}$. Reactions were stopped by the addition of $450 \mu$ stop solution (20 mM HEPES $\mathrm{pH} 7.5,20 \mathrm{mM}$ EDTA, $0.5 \mathrm{mM}$ cAMP) and the mixtures were filtered on $\mathrm{Al}_{2} \mathrm{O}_{3}$ columns, which included three washes with $1 \mathrm{ml}$ of $20 \mathrm{mM}$ HEPES pH 7.5 each to separate nucleotide substrates that were retained in the columns from cyclic nucleotides present in the filtrates. Filtrates were collected in $20 \mathrm{ml}$ scintillation vials. Sixteen millilitres scintillation liquid (HiSafe3, Perkin Elmer) were added before measuring ${ }^{33} \mathrm{P}$ in a TriCarb scintillation counter (Perkin Elmer). All reactions were performed in duplicates. Differences between c.p.m. values of most duplicates were around or $<10 \%$. S.d.'s between duplicates are indicated by error bars.

Muscle actin 99\% pure (designated MA-99) from rabbit skeletal muscle (Reference AKL99), or 99\% pure non-muscle actin from human platelets (Reference APHL99, designated A-99) was obtained from Cytoskeleton, Inc. Alternatively, we used actin from rabbit skeletal muscle prepared in one of our laboratories (designated MA-L) according to the procedure described ${ }^{48}$. For activity assays, all actin solutions were diluted in G-buffer supplemented with BSA at $0.1 \mathrm{mg} \mathrm{ml}^{-1}$.

Preliminary experiments to optimize reaction conditions showed that ExoY-FH was most active at $\mathrm{pH}$ values between 8 and 9 and in Tris- $\mathrm{HCl}$ as compared with HEPES or Na-phosphate and shows a broad optimal $\mathrm{NaCl}$ concentration (between 100 and $300 \mathrm{mM} \mathrm{NaCl}$ ).

Extracts from HeLa cells for activation of ExoY were prepared as follows: Cells grown in Dulbecco's modified Eagle's medium (DMEM) + 10\% fetal bovine serum were harvested after reaching $75 \%$ of confluence. One wash with PBS was followed by incubation in $10 \mathrm{ml} \mathrm{PBS}$ containing $0.01 \mathrm{M}$ EDTA for $5 \mathrm{~min}$ at $37^{\circ} \mathrm{C}$ before detaching the cells by gentle tapping of the flasks. Cells were collected by centrifugation and washed three times in PBS. The cell pellet was resuspended in $2 \mathrm{ml}$ of lysis buffer $(50 \mathrm{ml}$ Tris- $\mathrm{HCl} \mathrm{pH} \mathrm{7.5,300} \mathrm{mM} \mathrm{NaCl,} \mathrm{0.5 \%} \mathrm{NP50,} \mathrm{complete}$ EDTA-free protease inhibitor cocktail (Roche)) per ml of cell pellet volume, after which the cells were snap frozen in liquid nitrogen and stored at $-80^{\circ} \mathrm{C}$ or processed immediately. Frozen cells were allowed to thaw on ice, rotated at $4{ }^{\circ} \mathrm{C}$ for $20 \mathrm{~min}$ and centrifuged for $1 \mathrm{~h}$ at 18,000 r.p.m. in a SS34 rotor (Sorval). The supernatant was centrifuged at 100,000 r.p.m. at $4{ }^{\circ} \mathrm{C}$ for $1 \mathrm{~h}$ in a TLA-110 rotor (Beckmann). The resulting supernatant was filtered through a $0.45 \mu \mathrm{M}$ durapore polyvinylidene difluoride filter unit (Millipore) and dialysed against Tris- $\mathrm{HCl} /$ Triton/Glycerol buffer (TTG-buffer) containing $25 \mathrm{mM}$ Tris-HCl pH 8.0, 0.1\% Triton X-100, 10\% glycerol, $1 \mathrm{mM}$ DTT, $0.4 \mathrm{mM}$ phenylmethylsulphonyl fluoride). 
Insoluble material was removed by centrifugation at 18,000 r.p.m. in a SS34 rotor at $4{ }^{\circ} \mathrm{C}$ for $20 \mathrm{~min}$. HeLa cell extract prepared according to this protocol contained approximately $10 \mathrm{mg} \mathrm{ml}^{-1}$ of protein and was stored in aliquots at $-20^{\circ} \mathrm{C}$.

Extracts from S. cerevisiae were prepared from $100 \mathrm{ml}$ cultures grown in yeast extract peptone dextrose to an OD600 between 0.5 and 2, at which cells were harvested by centrifugation, washed once with water, and resuspended in $300 \mu \mathrm{l}$ yeast lysis buffer (50 mM Tris- $\mathrm{HCl} \mathrm{pH} 7.4,50 \mathrm{mM} \mathrm{KCl}, 1 \mathrm{mM}$ DTT, complete EDTA-free protease inhibitor cocktail (Roche)). Cells were subsequently vortexed for a total of $5 \mathrm{~min}$ (five times $1 \mathrm{~min}$ to prevent overheating) at $4{ }^{\circ} \mathrm{C}$. Debris were removed by centrifugation at 16,000 r.p.m. for $15 \mathrm{~min}$ at $4^{\circ} \mathrm{C}$. The resulting extract contained about $4 \mathrm{mg} \mathrm{ml}^{-1}$ protein and was stored at $-20^{\circ} \mathrm{C}$ after the addition of glycerol to a final concentration of $10 \%$.

Cycles of freezing and thawing did not seem to affect the activity of the cofactor necessary for ExoY activation in extracts from HeLa cells or S. cerevisiae.

Mg-ATP-actin was prepared from MA-L as follows: $90 \mu \mathrm{l}$ of MA-L at $22.22 \mu \mathrm{M}$ were added to $10 \mu \mathrm{l}$ of $10 \times$ concentrated buffer resulting in a final concentration of $40 \mu \mathrm{M} \mathrm{MgCl}_{2}$ and $0.4 \mathrm{mM} \mathrm{EGTA}$ and incubated for $10 \mathrm{~min}$ at room temperature and put on ice.

A $34 \mu \mathrm{M}$ solution of Mg-ADP-actin was prepared as follows: Ca-ATP-actin (MA-L) was converted to Mg-ATP-actin by adding $100 \times$ concentrated buffer resulting in a final concentration of $40 \mu \mathrm{M} \mathrm{MgCl}_{2}$ and $0.2 \mathrm{mM}$ EGTA and incubating for $10 \mathrm{~min}$ at room temperature. In all, $15 \mathrm{U} \mathrm{ml}^{-1}$ of Hexokinase (Roche) was added together with glucose to a concentration of $5 \mathrm{mM}$ followed by 30 min incubation on ice. The hexokinase inhibitor P1,P5-Di(adenosine- $5^{\prime}$ ) pentaphosphate (Ap5A) was then added to $10 \mu \mathrm{M}$ and the mixture was incubated for $5 \mathrm{~min}$ on ice. ADP and TCEP (tris(2-carboxyethyl) phosphine) was added to 0.2 and $2 \mathrm{mM}$, respectively. Mg-ADP-actin was diluted in G-ADP-buffer ( $5 \mathrm{mM}$ Tris$\mathrm{HCl} \mathrm{pH} 7.8,0.2 \mathrm{mM}$ ADP, $2 \mathrm{mM}$ TCEP, $30 \mu \mathrm{M} \mathrm{MgCl}_{2}$ ). Fifteen microlitres of the diluted actin solutions (Mg-ATP-actin or Mg-ADP-actin) were combined with $30 \mu \mathrm{l}$ of a mixture containing $1 \mathrm{ng}$ ExoY in reaction buffer to achieve final reaction buffer conditions of $50 \mathrm{mM}$ Tris- $\mathrm{HCl} \mathrm{pH} \mathrm{8.0,200} \mathrm{mM} \mathrm{NaCl}, 7.5 \mathrm{mM} \mathrm{MgCl} 2,2 \mathrm{mM}$ DTT and $0.5 \mathrm{mg} \mathrm{ml}^{-1}$ BSA.

Studies on the effect of profilin or latrunculin were performed with actin (MA-L) polymerized to steady state. For studies on the effect of profilin: (1) control reactions: $5 \mu \mathrm{l}$ of $5 \times$ concentrated buffer resulting in a final concentration of $45 \mu \mathrm{M} \mathrm{MgCl}_{2}$ and $0.4 \mathrm{mM}$ EGTA were added to $20 \mu \mathrm{l}$ actin at $16.7 \mu \mathrm{M}$ (diluted in G-buffer) and incubated for $10 \mathrm{~min}$ at room temperature. Twenty-five microlitres fresh $2 \times$ polymerization buffer (F2: $300 \mathrm{mM} \mathrm{KCl}, 40 \mathrm{mM} \mathrm{MgCl}_{2}, 10 \mathrm{mM}$ ATP and $10 \mathrm{mM}$ DTT) was added and samples were allowed to sit at room temperature for $2 \mathrm{~h}$ to allow polymerization to proceed to steady state. Varying amounts of the so-prepared F-actin were combined with F1-buffer (F1: $150 \mathrm{mM} \mathrm{KCl}, 20 \mathrm{mM}$ $\mathrm{MgCl}_{2}, 5 \mathrm{mM}$ ATP and $5 \mathrm{mM}$ DTT) to a total volume of $15 \mu \mathrm{l}$ and added to $30 \mu \mathrm{l}$ of a mixture containing $1 \mathrm{ng}$ ExoY in buffer to achieve final reaction buffer conditions of $50 \mathrm{mM}$ Tris-HCl pH 8.0, $200 \mathrm{mM} \mathrm{NaCl}, 7.5 \mathrm{mM} \mathrm{MgCl} 2,2 \mathrm{mM}$ DTT and $0.5 \mathrm{mg} \mathrm{ml}^{-1} \mathrm{BSA}$. After $30 \mathrm{~min}$ preincubation at $30^{\circ} \mathrm{C}$, reactions were started by the addition of GTP $\left(2 \mathrm{mM}\right.$, spiked with $\left[\alpha^{33} \mathrm{P}\right]$ GTP) and allowed to proceed for 10 min. (2) Reactions containing profilin: profilin was dialysed against G-buffer to remove the $\mathrm{KCl}$ present in the storage buffer before adding $5 \mu \mathrm{l}$ at $142.7 \mu \mathrm{M}$ directly to undiluted actin ( $6 \mu \mathrm{l} \mathrm{MA}$ at $55.88 \mu \mathrm{M}$ in G-buffer), incubated at room temperature for $10 \mathrm{~min}$ and diluted by adding $14 \mu \mathrm{l} \mathrm{G-buffer}$. Actin was not converted into

Mg-ATP-actin. Twenty-five microlitres fresh F2 buffer was added and 11.2, 7.5 or $5.6 \mu \mathrm{l}$ of this mixture were combined with G-buffer to a total volume of $15 \mu \mathrm{l}$ and used immediately in activity assays. At final actin concentrations of 1.5, 1 and $0.75 \mu \mathrm{M}$, profilin was present at 3,2 and $1.5 \mu \mathrm{M}$, respectively.

Latrunculin A was purchased from tebu-bio (produced by Focus Biomolecules). Studies with latrunculin were done similarly to those on profilin except that higher concentrations of actin (between 5.25 and $0.065 \mu \mathrm{M}$ final MA-L) were used and reaction buffer did not contain BSA. Reactions containing latrunculin were converted into Mg-ATP-actin after combining actin and latrunculin (in twofold access over actin) by $10 \mathrm{~min}$ incubation at room temperature. Samples containing latrunculin were incubated $2 \mathrm{~h}$ at room temperature as the corresponding controls. The mixture of latrunculin and actin was diluted to different concentrations in G-buffer containing latrunculin to ensure equal concentrations of latrunculin in all reactions. Control reactions lacking latrunculin contained dimethylsulphoxide at concentrations equivalent to that introduced with latrunculin.

Inhibition of actin assembly by latrunculin was verified by cosedimentation assays (Supplementary Fig. 3)

Pyrene-actin polymerization and depolymerization assays. Actin polymerization or depolymerization were monitored at $25^{\circ} \mathrm{C}$ by the increase or decrease in fluorescence, respectively, of $3-10 \%$ (polymerization) or $50 \%$ (depolymerization) pyrenyl-labelled actin $(\lambda e x c=340 \mathrm{~nm}, \lambda \mathrm{em}=407 \mathrm{~nm})$. Actin-Ca-ATP in G-buffer was converted just before the experiments into G-actin-Mg-ATP by adding 1/100 (vol./vol.) of ( $2 \mathrm{mM} \mathrm{MgCl}_{2}, 20 \mathrm{mM} \mathrm{EGTA}$ ). Polymerization assays were performed in a final F0-buffer containing $\left(0.1 \mathrm{M} \mathrm{KCl}, 2 \mathrm{mM} \mathrm{MgCl}_{2}, 30 \mathrm{mM}\right.$ Tris- $\mathrm{HCl} \mathrm{pH} 7.8$, $1 \mathrm{mM}$ TCEP, $1 \mathrm{mM}$ DTT), $5 \mathrm{mM}$ ATP or $2 \mathrm{mM}$ ADP and $4 \mathrm{mM} \mathrm{GTP}$, unless indicated otherwise in figure legends. Polymerization with Arp2/3 (Fig. 4d) and depolymerization were performed in a final F1-buffer containing $(0.1 \mathrm{M} \mathrm{KCl}, 8 \mathrm{mM}$ $\mathrm{MgCl}_{2}, 50 \mathrm{mM}$ Tris-HCl pH 7.8, $9 \mathrm{mM}$ TCEP, $1 \mathrm{mM}$ DTT, $\left.0.3 \mathrm{mM}\left(\mathrm{NH}_{4}\right)_{2} \mathrm{SO}_{4}\right)$,
10 to $15 \mathrm{mM}$ ATP or ADP, and 3 to $5 \mathrm{mM}$ GTP, unless indicated otherwise in figure legends. Fluorescence measurements were carried out in a Safas Xenius model FLX (Safas, Monaco) spectrophotometer, using a multiple sampler device. Dilution-induced depolymerization assays were performed by quickly diluting 4 to $68 \mu \mathrm{l}$ of 9 to $13 \mu \mathrm{M} 50 \%$ pyrenyl-labelled F-actin at steady state into a final volume of $160 \mu \mathrm{l}$ containing F1 buffer, ATP and the proteins of interest. Different fluorescence intensity levels were used in the two depolymerization assays of Fig. 4b.

Random mutagenesis. Random mutagenesis was performed using the GeneMorph II kit (Agilent) according to the instructions of the manufacturer. Error prone PCR was performed using primers 1060 and M13R on template p1387. ClaI/SalI-digested fragments were cloned into plasmid p1182 digested with the same enzymes and transformed into $E$. coli. Transformants $(\approx 4,000)$ were pooled for plasmid DNA extraction, which was subsequently transformed into S. cerevisiae SC483 to substitute wild-type actin with mutant alleles. This haploid S. cerevisiae strain lacks the chromosomal act-1 gene and contains plasmid p1177, which harbours the wild-type act 1 gene and a Ura3 marker ${ }^{35}$. Initial transformants were harvested and pooled after 2 days incubation at $30^{\circ} \mathrm{C}$ and re-plated on medium containing 5-fluoroorotic acid to select against the plasmid coding for wt actin. Colonies were pooled and kept as frozen stock at $-80^{\circ} \mathrm{C}$. An aliquot of this mutant pool stock solution was transformed in batch with plasmid p1654 coding for MycExoY-NanoLuc and plated on SG-agar supplemented with $0.05 \%$ glucose. Colonies were picked after 3-4 days and streaked on SG-agar. Forty of the initial 50 colonies survived under these conditions and were analysed for expression of ExoY by antiMyc western blots. Plasmid DNA from the 21 clones that did not show impairment of ExoY expression was transformed into E. coli selecting for the kmR marker of the plasmids carrying the actin mutant allele. Sequences of the act- 1 mutant alleles were then analysed.

Isolated plasmids (p1688 and p1689) carrying either one of the two distinct mutant alleles that were found (D25Y/D222G and D25N, respectively) as well as p1387 (wild-type actin) were transformed into SC483 to ensure a clean strain background. The strains obtained after elimination of the wild-type act 1 gene (SC690, SC691, and SC489) were used in stress tests to study potential effects of the actin mutant alleles on growth under different conditions and effects on cytotoxicity of ExoY expression.

Light microscopy and quantifications of F-actin content. HeLa cells were transiently transfected with AcGFP or ExoY ${ }^{\mathrm{K} 81 \mathrm{M}}$-AcGFP constructs. Transfection with ExoY' ${ }^{\text {wt }}$ construct resulted in cell death, which precluded the use of ExoY'st. Thirty-six hours later, cells were trypsinized and replated on fibronectin coated coverslips for $2 \mathrm{~h}$. After fixation and permeabilization, cells were stained using Acti-stain 670 fluorescent phalloidin (Cytoskeleton, Inc.). Confocal images were acquired by a Nipkow Spinning Disk Confocal system (Yokogawa CSU-X1-A1) mounted on an inverted microscope (Nikon Eclipse Ti-E) using a $\times 100$ Apochromat TIRF oil-immersion objective (NA: 1.49). Blue (491 nm Cobolt Calypso) and red (642 nm Toptica iBeam Smart 640-S) lasers were used for excitation of AcGFP and $670 \mathrm{~nm}$ fluorescent phalloidin, respectively. Images were recorded with an ORCA-Flash4.0 LT CMOS camera (Hamamatsu) and stacks were acquired with a step of $300 \mathrm{~nm}$ using MetaMorph 7.7 (Molecular Devices) under identical settings. The cross correlation analysis on the co-localization data was performed using PCC measured from AcGFP and $670 \mathrm{~nm}$ fluorescence inside the successive sections of the individual cells. The PCC is a quantitative measurement that estimates the degree of overlap between fluorescence signals obtained in two channels ${ }^{58}$. The quantification of the fluorescence intensity of stress fibres was obtained by analysing the bottom three slices after subtraction of background from the nearby cytoplasm. Total amount of F-actin was assessed by the intensity of phalloidin staining in the whole cell. Image analyses (region of interest selection as contours of the whole individual cells, intensity measurements, co-localization analyses) were performed using Icy software (Institut Pasteur, France Bio Imaging ${ }^{59}$. Statistical analysis was performed using Student's $t$-test as significance test, with $P \leq 0.001$.

For TIRF microscopy, HeLa cells were cultured in DMEM, $5 \% \mathrm{CO}_{2}$. Cells were transiently transfected with vinculin-mCherry ${ }^{60}$ and either GFP-C1 (Clontech, Palo-Alto, CA, USA) or ExoY ${ }^{\mathrm{K} 81 \mathrm{M}}$-AcGFP using Lipofectamine (Thermo Fisher, Carlsbad, CA, USA) as per the manufacturer's instructions. Cells were plated onto plasma cleaned coverslips $24 \mathrm{~h}$ before imaging. Images were acquired using a custom built TIRF microscope.

Data availability. The authors declare that the data supporting the findings of this study are available within the paper and its Supplementary Information files.

\section{References}

1. Engel, J. \& Balachandran, P. Role of Pseudomonas aeruginosa type III effectors in disease. Curr. Opin. Microbiol. 12, 61-66 (2009).

2. Hauser, A. R. The type III secretion system of Pseudomonas aeruginosa: infection by injection. Nat. Rev. Microbiol. 7, 654-665 (2009).

3. Burstein, D. et al. Novel type III effectors in Pseudomonas aeruginosa. MBio 6, e00161 (2015) 
4. Feltman, H. et al. Prevalence of type III secretion genes in clinical and environmental isolates of Pseudomonas aeruginosa. Microbiology 147, 26592669 (2001).

5. Yahr, T. L., Vallis, A. J., Hancock, M. K., Barbieri, J. T. \& ExoY, Frank DW. an adenylate cyclase secreted by the Pseudomonas aeruginosa type III system. Proc. Natl Acad. Sci. USA 95, 13899-13904 (1998).

6. Gottle, M. et al. Cytidylyl and uridylyl cyclase activity of bacillus anthracis edema factor and Bordetella pertussis CyaA. Biochemistry 49, 5494-5503 (2010).

7. Beckert, U. et al. ExoY from Pseudomonas aeruginosa is a nucleotidyl cyclase with preference for cGMP and cUMP formation. Biochem. Biophys. Res. Commun. 450, 870-874 (2014).

8. Ochoa, C. D., Alexeyev, M., Pastukh, V., Balczon, R. \& Stevens, T. Pseudomonas aeruginosa exotoxin $\mathrm{Y}$ is a promiscuous cyclase that increases endothelial tau phosphorylation and permeability. J. Biol. Chem. 287, 2540725418 (2012).

9. Lin, H. H. et al. Presence of the exoU gene of Pseudomonas aeruginosa is correlated with cytotoxicity in MDCK cells but not with colonization in BALB/ c mice. J. Clin. Microbiol. 44, 4596-4597 (2006).

10. Stevens, T. C. et al. The Pseudomonas aeruginosa exoenzyme Y impairs endothelial cell proliferation and vascular repair following lung injury. Am J Physiol Lung Cell Mol Physiol 306, L915-24 (2014).

11. Balczon, R. et al. Pseudomonas aeruginosa exotoxin Y-mediated tau hyperphosphorylation impairs microtubule assembly in pulmonary microvascular endothelial cells. PLoS One 8, e74343 (2013).

12. Cowell, B. A., Evans, D. J. \& Fleiszig, S. M. Actin cytoskeleton disruption by ExoY and its effects on Pseudomonas aeruginosa invasion. FEMS Microbiol. Lett. 250, 71-76 (2005).

13. Sayner, S. L. et al. Paradoxical cAMP-induced lung endothelial hyperpermeability revealed by Pseudomonas aeruginosa ExoY. Circ. Res. 95, 196-203 (2004).

14. Ganter, M. T. et al. Role of small GTPases and alphavbeta5 integrin in Pseudomonas aeruginosa-induced increase in lung endothelial permeability. Am. J. Respir. Cell. Mol. Biol. 40, 108-118 (2009).

15. Huber, P., Bouillot, S., Elsen, S. \& Attree, I. Sequential inactivation of Rho GTPases and Lim kinase by Pseudomonas aeruginosa toxins ExoS and ExoT leads to endothelial monolayer breakdown. Cell. Mol. Life Sci. 71, 1927-1941 (2014).

16. Ziolo, K. J. et al. Vibrio vulnificus biotype 3 multifunctional autoprocessing RTX toxin is an adenylate cyclase toxin essential for virulence in mice. Infect. Immun. 82, 2148-2157 (2014).

17. Berkowitz, S. A., Goldhammer, A. R., Hewlett, E. L. \& Wolff, J. Activation of prokaryotic adenylate cyclase by calmodulin. Ann. NY Acad. Sci. 356, 360 (1980).

18. Leppla, S. H. Anthrax toxin edema factor: a bacterial adenylate cyclase that increases cyclic AMP concentrations of eukaryotic cells. Proc. Natl Acad. Sci. USA 79, 3162-3166 (1982).

19. Barzu, O. \& Danchin, A. Adenylyl cyclases: a heterogeneous class of ATPutilizing enzymes. Prog. Nucleic Acid Res. Mol. Biol. 49, 241-283 (1994).

20. Arnoldo, A. et al. Identification of small molecule inhibitors of Pseudomonas aeruginosa exoenzyme S using a yeast phenotypic screen. PLoS Genet. 4, e1000005 (2008).

21. Luber, C. A. et al. Quantitative proteomics reveals subset-specific viral recognition in dendritic cells. Immunity 32, 279-289 (2010).

22. Pollard, T. D. Actin and actin-binding proteins. Cold Spring Harb. Perspect. Biol 8, a018226 (2016)

23. Coue, M., Brenner, S. L., Spector, I. \& Korn, E. D. Inhibition of actin polymerization by latrunculin A. FEBS Lett. 213, 316-318 (1987).

24. Yarmola, E. G., Somasundaram, T., Boring, T. A., Spector, I. \& Bubb, M. R. Actin-latrunculin A structure and function. Differential modulation of actinbinding protein function by latrunculin A. J. Biol. Chem. 275, 28120-28127 (2000).

25. Didry, D. et al. How a single residue in individual beta-thymosin/WH2 domains controls their functions in actin assembly. EMBO J. 31, 1000-1013 (2012).

26. Husson, C. et al. Multifunctionality of the beta-thymosin/WH2 module: $\mathrm{G}$-actin sequestration, actin filament growth, nucleation, and severing. Ann. NY Acad. Sci. 1194, 44-52 (2010).

27. dos Remedios, C. G. et al. Actin binding proteins: regulation of cytoskeletal microfilaments. Physiol. Rev. 83, 433-473 (2003).

28. Bugyi, B., Didry, D. \& Carlier, M. F. How tropomyosin regulates lamellipodial actin-based motility: a combined biochemical and reconstituted motility approach. EMBO J. 29, 14-26 (2010).

29. Olshina, M. A. et al. Plasmodium falciparum coronin organizes arrays of parallel actin filaments potentially guiding directional motility in invasive malaria parasites. Malar. J. 14, 280 (2015).

30. Ti, S. C., Jurgenson, C. T., Nolen, B. J. \& Pollard, T. D. Structural and biochemical characterization of two binding sites for nucleation-promoting factor WASp-VCA on Arp2/3 complex. Proc. Natl Acad. Sci. USA 108, E463471 (2011).

31. Pollard, T. D., Blanchoin, L. \& Mullins, R. D. Molecular mechanisms controlling actin filament dynamics in nonmuscle cells. Annu. Rev. Biophys. Biomol. Struct. 29, 545-576 (2000).

32. Steinmetz, M. O., Goldie, K. N. \& Aebi, U. A correlative analysis of actin filament assembly, structure, and dynamics. J. Cell. Biol. 138, 559-574 (1997)

33. Goudenege, D. et al. Comparative genomics of pathogenic lineages of Vibrio nigripulchritudo identifies virulence-associated traits. ISME J. 7, 1985-1996 (2013).

34. Shen, A. et al. Mechanistic and structural insights into the proteolytic activation of Vibrio cholerae MARTX toxin. Nat. Chem. Biol. 5, 469-478 (2009).

35. Belyy, A. et al. Roles of Asp179 and Glu270 in ADP-ribosylation of actin by Clostridium perfringens Iota toxin. PLoS ONE 10, e0145708 (2015).

36. Boeke, J. D., Trueheart, J., Natsoulis, G. \& Fink, G. R. 5-Fluoroorotic acid as a selective agent in yeast molecular genetics. Methods Enzymol. 154, 164-175 (1987).

37. Aktories, K., Lang, A. E., Schwan, C. \& Mannherz, H. G. Actin as target for modification by bacterial protein toxins. FEBS J. 278, 4526-4543 (2011).

38. Haglund, C. M. \& Welch, M. D. Pathogens and polymers: microbe-host interactions illuminate the cytoskeleton. J. Cell. Biol. 195, 7-17 (2011).

39. Drum, C. L. et al. Structural basis for the activation of anthrax adenylyl cyclase exotoxin by calmodulin. Nature 415, 396-402 (2002)

40. Karst, J. C. et al. Calmodulin-induced conformational and hydrodynamic changes in the catalytic domain of Bordetella pertussis adenylate cyclase toxin. Biochemistry 49, 318-328 (2010).

41. Behrmann, E. et al. Structure of the rigor actin-tropomyosin-myosin complex. Cell 150, 327-338 (2012).

42. Juris, S. J., Rudolph, A. E., Huddler, D., Orth, K. \& Dixon, J. E. A distinctive role for the Yersinia protein kinase: actin binding, kinase activation, and cytoskeleton disruption. Proc. Natl Acad. Sci. USA 97, 9431-9436 (2000).

43. Trasak, C. et al. Yersinia protein kinase YopO is activated by a novel G-actin binding process. J. Biol. Chem. 282, 2268-2277 (2007).

44. Lee, W. L., Grimes, J. M. \& Robinson, R. C. Yersinia effector YopO uses actin as bait to phosphorylate proteins that regulate actin polymerization. Nat. Struct. Mol. Biol. 22, 248-255 (2015).

45. Gietz, R. D. \& Woods, R. A. Transformation of yeast by lithium acetate/singlestranded carrier DNA/polyethylene glycol method. Methods Enzymol. 350, 8796 (2002).

46. Alberti, S., Gitler, A. D. \& Lindquist, S. A suite of Gateway cloning vectors for high-throughput genetic analysis in Saccharomyces cerevisiae. Yeast 24, 913919 (2007).

47. Husson, C., Renault, L., Didry, D., Pantaloni, D. \& Carlier, M. F. Cordon-Bleu uses WH2 domains as multifunctional dynamizers of actin filament assembly. Mol. Cell 43, 464-477 (2011).

48. Spudich, J. A. \& Watt, S. The regulation of rabbit skeletal muscle contraction. I. Biochemical studies of the interaction of the tropomyosin-troponin complex with actin and the proteolytic fragments of myosin. J. Biol. Chem. 246, 48664871 (1971).

49. Mizuno, H. et al. Rotational movement of the formin mDial along the double helical strand of an actin filament. Science 331, 80-83 (2014).

50. Casella, J. F., Maack, D. J. \& Lin, S. Purification and initial characterization of a protein from skeletal muscle that caps the barbed ends of actin filaments. J. Biol. Chem. 261, 10915-10921 (1986).

51. Gaucher, J. F. et al. Interactions of isolated C-terminal fragments of neural Wiskott-Aldrich syndrome protein (N-WASP) with actin and Arp2/3 complex. J. Biol. Chem. 287, 34646-34659 (2012).

52. Le Clainche, C. \& Carlier, M. F. Actin-based motility assay. Curr. Protoc. Cell. Biol Chapter 12 Unit 12.17.11-12.17-20 (2004).

53. Defenouillere, Q. et al. Cdc48-associated complex bound to 60S particles is required for the clearance of aberrant translation products. Proc. Natl Acad. Sci. USA 110, 5046-5051 (2013).

54. Cox, J. \& Mann, M. MaxQuant enables high peptide identification rates, individualized p.p.b.-range mass accuracies and proteome-wide protein quantification. Nat. Biotechnol. 26, 1367-1372 (2008).

55. Vallabhaneni, K. C. et al. Extracellular vesicles from bone marrow mesenchymal stem/stromal cells transport tumor regulatory microRNA, proteins, and metabolites. Oncotarget 6, 4953-4967 (2015).

56. Perkins, D. N., Pappin, D. J., Creasy, D. M. \& Cottrell, J. S. Probability-based protein identification by searching sequence databases using mass spectrometry data. Electrophoresis 20, 3551-3567 (1999).

57. Poullet, P., Carpentier, S. \& Barillot, E. myProMS, a web server for management and validation of mass spectrometry-based proteomic data. Proteomics 7, 2553 2556 (2007).

58. Zinchuk, V. \& Grossenbacher-Zinchuk, O. Quantitative colocalization analysis of fluorescence microscopy images. Curr. Protoc. Cell. Biol. 62 Unit 4.19.1114.19.14 (2011) 
59. Dufour, A., Thibeaux, R., Labruyere, E., Guillen, N. \& Olivo-Marin, J. C. 3-D active meshes: fast discrete deformable models for cell tracking in 3-D timelapse microscopy. IEEE Trans. Image Process 20, 1925-1937 (2011).

60. Elkhatib, N. et al. Fascin plays a role in stress fiber organization and focal adhesion disassembly. Curr. Biol. 24, 1492-1499 (2014).

61. Dereeper, A. et al. Phylogeny.fr: robust phylogenetic analysis for the nonspecialist. Nucleic Acids Res. 36, W465-W469 (2008).

\section{Acknowledgements}

We thank Alain Jacquier and Micheline Fromont-Racine for support and discussions. We thank Alexander Ishchenko for providing us with a first yeast extract, Scot Ouellette and Raynald Cossard for growing and transfecting HeLa cells, Bérengère Guichard for protein purification, Romé Voulhoux for chromosomal DNA of $P$. aeruginosa, Didier Mazel and Evelyne Krin for strain V. nigripulchritudo, the 3P5 proteomic facility, Emilie Cochet at the Institut Gustave Roussy for mass spectrometry analysis and Alexandre Chenal for help in data analysis. We wish to thank Prof. Sabine Rospert, Prof Klaus Aktories and Dr Yury Belyi for advice, strains and reagents used in yeast studies. This project was funded by the Institut Pasteur under \#PTR425 to U.M. and C.S. and by CNRS. A.B. was supported by a stipend from the Pasteur-Paris University (PPU) International PhD Program. We acknowledge the core facilities of Imagerie-Gif, (http://www.i2bc.paris-saclay.fr), supported by 'France-BioImaging' (ANR-10-INBS-04-01). This paper is dedicated to the memory of Vasily Ogryzko (1960-2016).

\section{Author contributions}

U.M., D.L., C.S., V.O. and L.R. conceived and U.M., D.L., C.S., V.O., A.B., V.D. and L.R. designed the experiments. A.B., D.R.-B., C.S., A.N., V.O., L.W., V.D, V.H., S.F., C.M.,
E.A., L.R. and U.M. performed the experiments and analysed the data. U.M., D.L., C.S. and L.R. wrote the paper. V.O. and V.D. edited the manuscript.

\section{Additional information}

Supplementary Information accompanies this paper at http://www.nature.com/ naturecommunications

Competing financial interests: The authors declare no competing financial interests.

Reprints and permission information is available online at http://npg.nature.com/ reprintsandpermissions/

How to cite this article: Belyy, A. et al. Actin activates Pseudomonas aeruginosa ExoY nucleotidyl cyclase toxin and ExoY-like effector domains from MARTX toxins. Nat. Commun. 7, 13582 doi: 10.1038/ncomms13582 (2016).

Publisher's note: Springer Nature remains neutral with regard to jurisdictional claims in published maps and institutional affiliations.

(c) (i) This work is licensed under a Creative Commons Attribution 4.0 cc. International License. The images or other third party material in this article are included in the article's Creative Commons license, unless indicated otherwise in the credit line; if the material is not included under the Creative Commons license, users will need to obtain permission from the license holder to reproduce the material. To view a copy of this license, visit http://creativecommons.org/licenses/by/4.0/

\footnotetext{
(C) The Author(s) 2016
} 